\title{
The Importance of Accounting Information in Portfolio Optimization
}

John R. M. Hand

H. Allen Andrew Distinguished Professor

Kenan-Flagler Business School

UNC Chapel Hill

Chapel Hill, NC 27599-3490

hand@unc.edu
Jeremiah Green

Ph.D. candidate

Kenan-Flagler Business School

UNC Chapel Hill

Chapel Hill, NC 27599-3490

jeremiah_green@unc.edu

\section{Abstract}

We study the economic importance of accounting information as defined by the value that sophisticated investors can extract from financial statements when maximizing their expected utility from holding a portfolio of U.S. equities. Our approach applies the elegant parametric portfolio policy (PPP) method of Brandt, Santa-Clara and Valkanov (2009) that models portfolio weights as a linear function of firm-specific characteristics. We find that three illustrative accounting-based characteristics - accruals, change in earnings, and asset growth - are economically important in that the set of optimal portfolio weights they generate yield an out-ofsample, pre-transactions-costs annual information ratio of 1.9 as compared to 1.5 for the standard price-based characteristics of firm size, book-to-market, and momentum. We also find that the pre-transactions-costs delevered hedge portion of the accounting-based optimal portfolio was especially valuable during two recent shocks. First, it earned 12\% during 2008 as compared to $3 \%$ for the price-based hedge and $-38 \%$ for the value-weighted market. Second, it fared far better than the price-based hedge during the Quant Meltdown of August, 2007.

This draft: Sep. 7, 2009

- We appreciate the comments of an anonymous referee, Mo Khan, and workshop participants at the 2009 AAA annual meeting and UNC Chapel Hill on a related but very different earlier paper. We are also very grateful to Michael Brandt, Pedro Santa-Clara and Ross Valkanov for sharing important parts of their MATLAB code with us. 


\section{Introduction \& Summary}

The majority of accounting research gauges the importance of accounting information to equity investors by either its usefulness in fundamental analysis and firm valuation (Penman, 2009), or the degree to which a publicly observed accounting signal is able to predict future abnormal stock returns (Bernard and Thomas, 1989, 1990; Lee, 2001).

In this paper we instead define the economic importance of accounting information as the value that a sophisticated investor can extract from firm-specific financial statement data when maximizing his expected utility from holding a portfolio of U.S. equities. As such, our paper directly studies the extent to which portfolio performance may be improved by using accounting information. Under our definition, accounting data is economically important if it leads the investor to materially tilt his portfolio weights away from the value-weighted market and toward under- or over-weightings that are predictably related to firm-specific, publicly available financial statement data items.

Relatively few papers in finance and accounting adopt a portfolio-tilt approach to evaluating the significance of investment signals. And among those that do, the dominant method has been to tilt portfolio weights toward factor mimicking portfolios, not firm-specific characteristics. ${ }^{1}$ The main reason for this is that incorporating firm characteristics into traditional mean-variance analysis (Markowitz, 1952) requires modeling every firm's expected return, variance and covariances as a function of those characteristics. Not only is this an intimidating task given the number of elements involved, but Markowitz portfolio solutions are notoriously unstable and often yield error-maximizing extreme weights (Michaud, 1989). While these problems can to some extent be mitigated by either applying shrinkage techniques to parameter estimates, imposing a factor structure onto returns, or imposing pragmatic constraints on the magnitude of permissible portfolio weights, they are severe enough to dissuade all but large sophisticated quantitative asset managers from optimizing their portfolios using firm-specific characteristics.

The notable exception to this seemingly dismal picture is the recent work of Brandt, Santa-Clara and Valkanov (BSCV, 2009). BSCV develop a simple yet ingenious parametric portfolio policy (PPP) technique that directly models stocks' portfolio weights as a linear function of firm characteristics. They then estimate the policy's few parameters by maximizing the average utility that an optimizing investor would have realized had she implemented the policy over the

\footnotetext{
${ }^{1}$ Grinold (1992) finds that in four out of five countries investors can substantially improve the in-sample Sharpe ratio of their tangency equity portfolio by tilting toward volatility, momentum, size and value factor portfolios. Similarly, Haugen and Baker (1996) use expected returns estimated from non-CAPM multi-factor models to construct optimized portfolios that in-sample dominate the mean-variance locations of capitalization-weighted market index for the US, UK, France, Germany and Japan. Korkie and Turtle (2002) investigate the extent to which dollar-neutral 'overlay' assets created out of Fama-French market capitalization and value portfolios can expand the in-sample efficient frontier. Kothari and Shanken (2002) explore the empirical limitations of the CAPM by estimating the degree to which investors should tilt their portfolios away from the market index in order to exploit the apparently anomalous returns in value, momentum and size-based trading strategies. Mashruwala et al. (2006) apply Kothari and Shanken's approach to estimating the optimal in-sample tilt toward a long/short accrual hedge portfolio strategy. They find that an investor would invest approximately 50\% in the value-weighted index and 50\% in the long/short accrual hedge portfolio, thereby earning an in-sample additional $3.2 \%$ per year on their overall portfolio of U.S. equity. Finally, Hirshleifer et al. (2006) find that an accrual factor-mimicking portfolio materially increases the Sharpe ratio of the ex-post mean-variance tangency portfolio facing investors.
} 
sample period. The characteristics they illustrate their PPP method with are firm size, book-tomarket and momentum. BSCV's results indicate that book-to-market and momentum are highly significant in explaining portfolio tilt weights and produce a certainty-equivalent out-of-sample return of $5.4 \%$ per year incremental to that of the value-weighted market.

A key source of the benefits realized from BSCV's PPP method is its ability to simultaneously capture the relations between firm-specific characteristics and expected returns, variances and covariances since all these moments affect the distribution of the optimized portfolio's returns. The PPP method allows a given firm-specific financial statement data item to tilt a stock in two ways: through generating alpha (long or short) and/or through reducing portfolio risk. In contrast, a conventional dollar neutral long-short hedge portfolio constructed to test the efficiency of the stock market with respect to the same financial statement data item does not take portfolio risk reduction into account, especially if there are multiple financial statement data items that the investor is optimizing over. It should also be noted that the PPP method is not equivalent to testing whether a firm-specific accounting-based or price-based signal is crosssectionally related to the conditional moments of stock returns. This is because a signal may be correlated with the first and second moments of stock returns in offsetting ways with the result that the investor's conditionally optimal portfolio weights are unrelated to the signal.

The goal of our paper is to use BSCV's PPP method to model stocks' portfolio weights as a linear function of three illustrative firm-specific accounting-based signals: accruals, change in earnings, and asset growth. We compare and contrast the total and incremental importance of the accounting-based signals to those of an illustrative set of price-based signals by modeling the weights as a linear function of not just accruals, change in earnings, and asset growth, but also firm size, book-to-market and momentum.

Using monthly return data on U.S. stocks between 1965 and 2008, we find that accruals, change in earnings and asset growth are economically important in that the portfolio tilt weights they generate yield a 34-year (1975-2008) out-of-sample pre-transaction-costs annual information ratio of 1.9. This compares favorably to the information ratio of 1.5 achieved by firm size, bookto-market, and momentum. When investors optimize over all six characteristics the information ratio increases to 2.0. Such information ratios rank in the top decile of before-fee information ratios according to statistics reported by Grinold and Kahn (2000, Table 5.1).

The delevered hedge portion of the portfolio optimized over all six firm characteristics yields out-of-sample pre-transactions-costs return that has a mean raw (alpha) return of $11.3 \%(13.2 \%)$ per year, a standard deviation (residual standard deviation) of 5.9\% (6.2\%), and a Sharpe ratio (information ratio) of 1.9 (2.1). The long and the short sides of this hedge portfolio contribute about equally to the size of the overall mean hedge return. However, we find that when shortsales are disallowed, the performance of the optimal portfolios suffers considerably. The out-ofsample annual information ratio of the price-based characteristics optimal portfolio drops from 1.5 to 0.8 , and that of the accounting-based characteristics optimal portfolio plummets from 1.7 to 0.1 . This indicates that being able to short sell is particularly vital for investors looking to extract value from firm-specific accounting information. 
Consistent with its sizeable and stable performance we find that the (delevered) hedge portion of the accounting-based optimal portfolio performed well during two recent and severely negative shocks to hedge funds. First, the accounting-based hedge portfolio earned 12\% during 2008 versus $3.4 \%$ for the price-based hedge and $-38 \%$ for the value-weighted market. Second, it fared markedly better than the price-based hedge during the Quant Meltdown of July and August, 2007 (Khandani and Lo, 2007, 2008). Over the full two-month period, the accounting-based hedge portfolio earned $-0.2 \%$ as compared to $-3.9 \%$ for the price-based hedge portfolio, and experienced a daily standard deviation of hedge returns of $0.4 \%$ and $1.7 \%$, respectively. We suggest that one reason for the favorable performance of the accounting-based hedge portfolio during August 2008 is that fewer hedge funds explicitly construct their trading strategies using financial statement data. As a result, our accounting-based hedge returns were less affected by the combination of strategy-crowding and rapid, intense deleveraging that hit hedge funds that were heavily invested in strategies predicated around firm size, book to market, and momentum.

From our analyses we conclude if the economic importance of accounting information is defined by the value that sophisticated investors can extract from financial statements when maximizing the utility they expect from a portfolio of U.S. equities, then accounting information is indeed important because optimally tilting a value-weighted portfolio toward firms with certain characteristics produces returns that are both high and stable. Our evidence also suggests that accounting-based characteristics seem particularly valuable in periods when severe negative shocks are experienced in the stock market as a whole, or by hedge funds in particular. We show that there may be large returns available to sophisticated investors as long as they can short-sell from exploiting the illustrative financial statement signals that we study. We also suspect that even better after-transactions costs returns can be earned by, for example, trading much closer to when financial statements are first made public, directly including transactions costs in the portfolio optimization, and using a larger set and more diverse of accounting-based signals.

The remainder of the paper is structured as follows. In section 2 we explain the intuition and algebra of BSCV's PPP method, and discuss its strengths and limitations. We describe the data we use and our implementation timeline in section 3, and our empirical results in section 4 . In section 5 we outline some caveats to our analyses. We conclude in section 6.

\section{The parametric portfolio policy (PPP) method of Brandt, Santa-Clara and Valkanov (2009)}

\subsection{Basic structure of the PPP method}

The PPP method begins by assuming that at every date $t$ the investor chooses a set of portfolio weights $\left\{w_{i t}\right\}_{i=1}^{N_{t}}$ over a set of stocks $N_{t}$ so as to maximize the conditional expected utility of that portfolio's one-period ahead return $r_{p, t+1}:^{2}$

$$
\max _{\left\{w_{i t}\right\}_{i=1}^{N_{t}}} \mathrm{E}_{t}\left[u\left(r_{p, t+1}\right)\right]=\mathrm{E}_{t}\left[u\left(\sum_{i=1}^{N_{t}} w_{i t} r_{i, t+1}\right)\right]
$$

\footnotetext{
${ }^{2}$ It should be noted - and BSCV emphasize that - the PPP method can accommodate all kinds of objective functions, not just that chosen per equation (1), such as maximization of the portfolio's Sharpe or information ratio.
} 
What distinguishes the PPP approach from a conventional mean-variance analysis (Markowitz, 1952) is the proposition that the investor's optimal portfolio weights can be parameterized as a function of a vector of stocks' characteristics $x_{i t}$ observed at $t$ :

$$
w_{i t}=f\left(x_{i t} ; \theta\right)
$$

As detailed by BSCV, the main conceptual advantages of the PPP approach are that it avoids the very difficult task of modeling the joint distribution of returns and characteristics; it dramatically reduces the dimensionality of the optimization problem; it simultaneously takes into account the relations between firm characteristics and all return moments; and it can accommodate all sorts of investor objective functions. There are also several practical advantages to the PPP method. It is easy and fast to implement in terms of computer run-time; it produces out-of-sample results that are typically only slightly worse than their in-sample counterparts because the parsimonious number of parameters involved reduces the risk of overfitting; it does not typically produce extreme portfolio weights; and it can be readily modified to allow for short-sale constraints, transactions costs, and non-linear parameterizations of equation (2) such as interactions between firm-characteristics and/or conditioning on macroeconomic variables.

Our focus in this study is on two illustrative sets of firm-specific attributes. The first consists of three accounting-based characteristics (ABCs) that are entirely and only contained in a firm's financial statements: accruals, change in earnings, and asset growth. The second set consists of three price-based characteristics (PBCs) that are partially or fully defined using a firm's stock price or stock return: market capitalization, book-to-market, and momentum.

Following BSCV, we adopt a linear specification for the portfolio weight function:

$$
w_{i t}=\bar{w}_{i t}+\frac{1}{N_{t}} \theta^{\mathrm{T}} \hat{x}_{i t}
$$

where $\bar{w}_{i t}$ is the weight of stock $i$ in a benchmark portfolio, which we take to be the valueweighted equity market $\mathrm{VW}, \theta$ is a vector of coefficients, and $\hat{x}_{i t}$ are the characteristics of stock $i$ after they have been cross-sectionally standardized at $t$. Equation (3) also expresses the idea of active portfolio management since $\theta^{\mathrm{T}} \hat{x}_{i t}$ describe the tilts - whether positive or negative - of the optimal portfolio weights from VW. Moreover, since the tilt weights must sum to zero, the difference between the return on the optimal portfolio $r_{p, t+1}$ and the return $r_{m, t+1}$ on $\mathrm{VW}$ represents the return to a long/short levered hedge portfolio lev $_{h, t+1}$ :

$$
r_{p, t+1}=\sum_{i=1}^{N_{t}} \bar{w}_{i t} r_{i, t+1}+\sum_{i=1}^{N_{t}}\left(\frac{1}{N_{t}} \theta^{\mathrm{T}} \hat{x}_{i t}\right)=r_{m, t+1}+\operatorname{rlev}_{h, t+1}
$$

In order to calibrate hedge returns across the different optimal portfolios generated by applying the PPP method to different sets of firm characteristics, we delever rlev $_{h, t+1}$ by separately calculating the returns on the long and short sides of the hedge, $r_{h}^{\text {Long }}$ and $r_{h}^{\text {Short }}$ respectively: 


$$
r l e v_{h, t+1}=o p t_{-} l e v_{h, t+1} \times\left(r_{h t}^{\text {Long }}+r_{h t}^{\text {Short }}\right)
$$

where

$$
\begin{gathered}
r_{h t}^{\text {Long }}=\sum_{j=1}^{N L_{t}} w_{j t}^{L} r_{j t} \quad \text { and } \quad r_{h t}^{\text {Short }}=\sum_{k=1}^{N S_{t}} w_{k t}^{S} r_{k t} \\
w_{j t}^{L}=\frac{w_{j t}}{\sum_{j=1}^{N L_{t}} w_{j t}} \quad \text { and } \quad w_{k t}^{S}=\frac{w_{k t}}{\sum_{k=1}^{N S_{t}} w_{k t}}
\end{gathered}
$$

and $N L_{t}\left(N S_{t}\right)$ is the number of firms at time $t$ with a positive (negative) tilt weight $\theta^{\mathrm{T}} \hat{x}_{i t}>0$ $\left(\theta^{\mathrm{T}} \hat{x}_{i t}<0\right)$. Then the delevered hedge return on the optimal portfolio $r_{h, t+l}$ is:

$$
r_{h, t+1}=r_{h t}^{\text {Long }}+r_{h t}^{\text {Short }}
$$

and the leverage of the optimal portfolio is:

$$
o p t_{-} l e v_{h, t+1}=\frac{\text { rlev }_{h, t+1}}{r_{h, t+1}}
$$

As emphasized by BSCV, a key feature of the parameterization in equation (2) is that $\theta$ is constant across assets and through time. This means that the conditional optimization with respect to $w_{i t}$ in equation (1) can be rewritten as an unconditional optimization with respect to $\theta$. Thus, for a given utility function the optimization problem translates to empirically estimating $\theta$ in equation (10) below over the sample period:

$$
\max _{\theta} \frac{1}{T} \sum_{t=0}^{T-1} u\left(\sum_{i=1}^{N_{t}}\left(\bar{w}_{i, t}+\frac{1}{N_{t}} \theta^{\mathrm{T}} \hat{x}_{i t}\right) r_{i, t+1}\right)
$$

Following BSCV, we assume the investor's utility function is such that he has constant relative risk-aversion preferences over wealth, where following BSCV we set $\gamma=5$ :

$$
u\left(r_{p, t+1}\right)=\frac{\left(1+r_{p, t+1}\right)^{1-\gamma}}{1-\gamma}
$$

\section{Data and implementation timeline}

\subsection{Variable definitions and sample selection criteria}

We collect financial statement data from the Compustat annual industrial file; monthly stock returns, including delisting returns, from CRSP monthly files; and the one-month Treasury bill rate from the Fama-French factor data set at WRDS. We select all Compustat variables from 
fiscal year 1964 (and lagged variables from 1963) through fiscal year 2007 together with CRSP data from Jan. 1965 through Dec. 2008. Following BSCV, we restrict the investor's opportunity set to U.S. stocks and do not include the risk-free asset because to a first-order approximation including the risk free asset affects only the leverage of the optimized portfolio.

Panel A of Table 1 defines the illustrative firm characteristics that we employ to assess the economic importance of accounting information using the PPP method. Firm size MVE is defined as the market value of common equity at the firm's fiscal year end (Banz, 1981; Reinganum, 1981). Book-to-market BTM is the fiscal year end book value of common equity scaled by MVE (Stattman, 1980; Rosenberg, Reid and Lanstein, 1985). Momentum MOM is taken to be the cumulative raw return for the 12 months ending four months after the most recent fiscal year end (Jegadeesh, 1990; Jegadeesh and Titman, 1993). When the statement of cash flows is available, annual accruals ACC are net income less operating cash flow scaled by average total assets; otherwise per Sloan (1996) we set ACC $=\Delta$ current assets $-\Delta$ cash $\Delta$ current liabilities $-\Delta$ debt in current liabilities $-\Delta$ taxes payable $-\Delta$ depreciation all scaled by average total assets (where if any of the balance sheet based accrual components is missing we set it to zero). The change in annual earnings UE is simply earnings in the most recent fiscal year less earnings one year prior, scaled by average total assets (Ball and Brown, 1968; Foster, Olsen and Shevlin, 1984). Lastly, asset growth AGR is defined to be the natural log of total assets at the end of the most recent fiscal year less the natural log of total assets one year earlier (Cooper, Gulen and Schill, 2008, 2009).

Panel B reports the number of observations we start with and how many are eliminated as we require firms first to have all the price-based data items, then second all the accounting-based data items. Each step removes approximately $9 \%$ of the initial total data set that requires only the availability of monthly stock returns. However, we also follow BSCV by also deleting the smallest 20\% of firms as measured by MVE since such firms tend to have low liquidity, high bid-ask spreads and disproportionately high transactions costs. As shown by the graph underneath panel B, the final number of firms varies greatly by year, rising from a low of only 276 in 1965 to a peak of 5,615 in 1998. The average number of firms per year is 3,373.

\subsection{Implementation timeline}

In this section we describe how we line up stock returns and financial statement data in real-time so as to be able to estimate the parameters of BSCV's PPP method, and the approach we take to generating out-of-sample returns.

For each month $t$ over the period Jan. 1965-Dec. 2008 we define the annual accountingbased and finance-based firm characteristics that would have been available to investors in realtime at the end of month $t$. In doing so, we assume that investors have price-based information up to the end of month $t$, and that accounting-based information is available with a six-month lag past a firm's fiscal year-end. For example, at the end of Aug. 1993, we assume that investors have annual accounting information for all firms with fiscal years ending on or before Feb. 28, 1993. For firms with fiscal years ending Mar. 1 through Aug. 31, we assume that the most recently available annual accounting information available to investors is for the prior fiscal year end. For example, the accounting information available to investors at the end of Aug. 1993 for 
a firm whose fiscal year-end is Mar. 31, 1993 will be from the firm's Mar. 31, 1992 annual financial statements. Such data will therefore be quite stale. While we expect this staleness to bias against our finding economic significance for accounting information in portfolio optimization, we impose this constraint in order to avoid look-ahead problems as much as possible, and also to align our methods with those of BSCV and most of the finance literature. We add to this conservatism by measuring not just firm characteristics ACC, UE and AGR using a six-month delay rule, but also MVE and BM (that is, we do not update the market value of equity to month $t$, or Aug. 1993 in the example above). The remaining price-based characteristic, MOM, is measured with a one month lag relative to month $t$. Figure 1 provides a visual representation of our implementation timeline for a firm with a 12/31 fiscal year-end.

We transform all firm characteristics in order to make standardized across-characteristic comparisons, and to mitigate the influence of outliers in the PPP estimation procedures. Each characteristic is ranked every month using all firms that have a valid stock price on CRSP at the end of the prior month. Our ranking is into percentiles (0-99) which we then divide by 99 . We then subtract 0.5 from the ranked and scaled characteristics. This assures that the characteristics have a mean of zero and have a constant distribution over time.

We collect stock returns for each month $t+1$. Returns for month $t+1$ are adjusted for delisting by compounding the last month's return and the delisting return if available on CRSP. If the month of the delisting return does not have a return on CRSP, we set the return equal to the delisting return. If a stock is delisted and no delisting return is available on CRSP, we set the return equal to $-35 \%$ for NYSE stocks and $-55 \%$ for NASDAQ stocks (Shumway and Warther, 1999). When value weighting returns to create portfolio weights for each month $t$, we use the firm's market capitalization at the prior month's close $(t-1)$.

The in-sample results we report use the 408 monthly returns between Jan. 1975 and Dec. 2008. That is, the full period Jan. 1975-Dec. 2008 is used to estimate one parameter set $\theta$ in equation (2) that linearly links the investor's optimal portfolio weights to firms' accountingbased and/or price-based characteristics.

The out-of-sample results we report are based on a "quasi-fixed" time period. We conform to the fixed in-sample 408 month window Jan. 1975-Dec. 2008 in terms of estimating the out-of-sample returns that could theoretically have accrued to an investor, but use a partiallyrolling parameter estimation period. Specifically, for each month in the first year of the out-ofsample period, Jan.-Dec. 1975, we use data from Jan. 1965-Dec. 1974 to estimate the parameter set $\theta_{1965-74}$ and then combine $\theta_{1965-74}$ with the (standardized and monthly varying) firm characteristics to generate out-of-sample firm returns and returns on the optimized portfolio for Jan.-Dec. 1975. Then for each month in the next year of the out-of-sample period, Jan.-Dec. 1976, we roll the ending point (but not the beginning point) of the historical data forward one year through Dec. 1975 and estimate the parameter set $\theta_{1965-75}$ and use $\theta_{1965-75}$ together with the (standardized and monthly varying) firm-characteristics to generate out-of-sample firm-specific returns and the returns on the optimized portfolio for Jan.-Dec. 1976. And so on. 


\section{Empirical results}

\subsection{Baseline findings (all available firms, no short-sale constraints, no transactions costs)}

Table 2 and Figure 2 provide our baseline findings. They are baseline in that they emerge from applying BSCV's PPP method to the average of approximately 3,286 firm observations per month without imposing any short-sale restrictions or transactions costs.

As explained in section 3.2, BSCV's PPP method applied out-of-sample yields a timeseries of both annual optimal portfolio policy parameters and monthly value-weighted firm characteristics. For the optimization that takes both accounting- and price-based firm characteristics into account, we plot these in Figure 2. Panel A shows that the estimated portfolio policy parameters are relatively stable over time, with the exception of the Internet peak-and-crash years 2000 and 2001. Panel B indicates a similar picture - that is, relative stability over time in the value-weighted characteristics of firms in the optimal portfolio, except 2000 and 2001.

Panel A of Table 2 reports parameter estimates and descriptive statistics on portfolio weights, and firm characteristics across the value-weighted market VW, our PPP in-sample data period, and the averages of the time-series of 408 individual monthly out-of-sample PPP results. VW is defined over our data set (see panel B of Table 1), not the unrestricted CRSP universe. In panel A, for the PPP in-sample columns what is reported is one $\theta$ per firm characteristic, estimated over the full sample period Jan. 1975-Dec. 2008. In contrast, what is reported in the PPP out-of-sample columns is the average of $34 \theta$ s, one per year over the full sample period. The standard errors for the in-sample columns are taken from the sample asymptotic covariance matrix of the optimization because the linear portfolio policy in equation (3) satisfies a first-order condition that allows the maximum expected utility vector of parameter estimates to be interpreted as a method of moments estimate (Hansen, 1982). ${ }^{3}$ The standard errors for the outof-sample columns are the average of the 408 monthly time-series of the in-sample partiallyrolling parameter estimation periods. ${ }^{4}$

Following the portfolio policy parameter estimates, for PPP in-sample (out-of-sample) we report the (average) monthly absolute weight in the optimal portfolio, the (average) monthly maximum and minimum weights, the (average) total short weights, and the (average) fraction of negative weights. The last section of panel A reports the time-series average of the monthly cross-sectional value weighted averages of the firms' ranked and scaled characteristics in the optimal portfolio. Positive values reflect an average emphasis toward firms with greater amounts of the characteristic. For example, a positive value for the characteristic MVE indicates that in that the optimal portfolio is on average weighted toward larger firms.

Inspection of panel A of Table 2 indicates several things. First, both in-sample and outof sample two out of three price-based and two out of three accounting-based parameter estimates lie more than two standard errors from zero (BTM, MOM, UE and AGR). Second,

\footnotetext{
${ }^{3} \mathrm{BSCV}$ indicate that they find that bootstrapped standard errors give more conservative (but nevertheless quite similar) results. We plan on also computing bootstrapped standard errors in the next version of our paper.

${ }^{4}$ As such, the out-of-sample standard errors are not out-of-sample in the usual sense.
} 
accruals ACC is not one of them. This may be due to the fact that hedge returns to accruals have died out in recent years (Green, Hand and Soliman, 2009). Third, when all six characteristics are included, only the parameter estimates for BTM, UE and AGR remain two standard errors from zero. Fourth, the PPP method yields non-extreme maximum (around 3.1\%) and minimum (around $-1 \%$ ) portfolio weights. Fifth, accounting-based characteristics lead to about twice as much more short-selling than do price-based characteristics. Lastly, across all estimated optimal portfolios, the fraction of stocks sold short ranges between $45 \%$ and $48 \%$. This is consistent with studies that show that the proportion of risky assets held short in both the mean-variance tangency portfolio and the minimum variance portfolio tends in the limit to 50\% where there are no constraints on short selling (Levy, 1983; Green and Hollifield, 1992; Levy and Ritov, 2001).

Panel B reports statistics on the returns generated by the optimal portfolios. The first section provides the certainty equivalent of the optimal portfolio's mean annualized return; the mean and standard deviation of the annualized return, together with the portfolio's annualized Sharpe ratio, alpha, beta, residual standard deviation, and information ratio. Note that following BSCV, the annualized return is defined as the simple sum of the calendar year's monthly returns. The second section reports how we compute the "managed" hedge portfolio return, defined per equation (4) as the optimized return less the VW market return. The third and fourth sections of panel B display the components of, and statistics based on, the delevered hedge return derived in equations (6)-(8), which we simply refer to as the "hedge return" or "hedge $r$ ". These items then allow one to compute the leverage of the managed hedge return per equation (9).

Inspection of panel B of Table 2 illuminates several noteworthy findings. First, the magnitudes of the mean pre-transactions-costs returns from all the PPP optimized portfolios range from large to enormous, both in- and out-of-sample. It should of course be borne in mind though that we saw in panel A that the large amounts of short selling involved in these portfolios means that they are highly levered. Consequently the standard deviations of returns from the PPP optimized portfolios are also large. Second, the annualized Sharp ratios and information ratios are quite large for all optimal portfolios. The out-of-sample SRs (IRs) of the optimal portfolios created using PBCs, ABCs and ABCs+PBCs are 1.36 (1.54), 1.71 (1.74), and 1.89 (2.02), respectively. ${ }^{5}$ Information ratios of this magnitude rank in the top decile of before-fee information ratios according to statistics reported by Grinold and Kahn (2000, Table 5.1).

Third, the delevered out-of-sample hedge return components of the PBC, ABC, and $\mathrm{PBC}+\mathrm{ABC}$ optimal portfolios are impressively large and have low time-series variability. For example, the annualized mean (standard deviation) $\mathrm{ABC}$ hedge return is $8.8 \%$ (4.6\%), while the corresponding amounts for the $\mathrm{PBC}+\mathrm{ABC}$ hedge return are $11.3 \%(5.9 \%)$. The t-statistics for the mean hedge returns far exceed 2 . These findings suggest that at least on a pre-transactionscost basis, it would be rare for either hedge strategy to earn a negative raw return. We also note that the long and short sides yield approximately equal alphas to the hedge portfolio across all three optimal portfolios both in- and out-of-sample.

\footnotetext{
${ }^{5}$ The Sharpe ratios we report are "standard" in the sense that they assume that the underlying portfolio monthly returns are distributed iid. We also compute but do not report Sharpe ratios adjusted to take into account first-order autocorrelation that may be present (Lo, 2002). They are typically slightly lower than those reported in our Tables.
} 
Fourth, adjusting the hedge returns for market risk yields even stronger results. Specifically, the out-of-sample information ratios for the $\mathrm{PBC}, \mathrm{ABC}$ and $\mathrm{PBC}+\mathrm{ABC}$ hedge portfolios are $1.54,1.88$ and 2.13 , respectively.

Overall, we conclude from the baseline results reported in Table 2 that not only does BSCV's PPP method work well for price-based firm characteristics on an out-of-sample basis, but it works even better for accounting-based firm characteristics, and even better still when accounting-based and price-based characteristics are exploited at the same time. We provide a visual representation of this conclusion in Figure 3, where we plot the log of the cumulative outof-sample monthly ABC, PBC and PBC+ABC optimized hedge portfolios. We also plot the log of the cumulative value-weighted market return for purposes of comparison. Visual inspection of Figure 3 clearly demonstrates that the $\mathrm{ABC}, \mathrm{PBC}$ and $\mathrm{PBC}+\mathrm{ABC}$ hedge portfolios on average deliver positive and remarkably smooth returns (with the exception of the PBC hedge portfolio during the 2000-2001 peak period of the Internet bubble). It can also be readily seen that the $\mathrm{ABC}$ and $\mathrm{PBC}+\mathrm{ABC}$ hedge portfolios especially offer far smoother returns than the valueweighted market, reflecting their having - per Table 2-a four times larger Sharpe ratio.

\subsection{Results when the set of firms is restricted to the largest 500 by market capitalization}

In Table 3 we report the results of restricting the set of firms over which the BSCV PPP optimization is estimated to be the largest 500 firms by market capitalization. ${ }^{6}$ Our goal is to assess the robustness of the baseline results reported in Table 2 to a proxy for the most liquid and cheapest-to-trade-in firms.

Focusing on the out-of-sample section of panel A, we note that with the exception of asset growth, the parameter estimates are lower than found in Table 2 where no restriction was placed on firm size. We find that while the parameter estimates on all three price-based characteristics are insignificantly different from zero, those on change in earnings (UE) and asset growth (AGR) are significantly positive and negative, respectively. The decline in parameter significance follows through into panel B in the sense that we observe markedly lower Sharpe ratios, information ratios, and unlevered hedge returns, particularly for portfolios optimized on only price-based firm characteristics. This said, we do find that the pre-transactions-costs, outof-sample Sharpe and information ratios of portfolios optimized on only accounting-based firm characteristics are respectable at 0.95 and 0.98 , respectively.

\subsection{Results when short sales are disallowed}

The ability to sell short is widely recognized in the academic and practitioner literatures as offering significant improvements in the expected returns and/or risk of a portfolio (Levy, 1983; Green and Hollifield, 1992; Alexander, 1993; Jacobs and Levy, 1993, 1997; Levy and Ritov, 2001; Jones and Larsen, 2004). With this in mind, in Table 4 we report the results of applying the BSCV PPP optimization when short selling is disallowed. We note that disallowing short selling is not the same thing as restricting the weights in the hedge return component of the

\footnotetext{
${ }^{6}$ Specifically, each month we compute the market value of each firm's common stock based on the closing stock price at the end of the previous month. We then retain only the largest 500 firms.
} 
optimized portfolio to be positive. Disallowing short selling simply means that stocks can be underweighted relative to the value-weighted market only down to a zero total weighting.

The key findings in Table 4 are that [1] the Sharpe ratios of price-based optimal portfolios decline by just under half their magnitudes in Table 2 (e.g., the out-of-sample Sharpe ratio of the price-based optimal portfolio falls from 1.36 in table 2 to 0.76 in Table 4), and [2] the Sharpe ratios of accounting-based optimal portfolios plummet to no better than that of the valueweighted market (e.g., the out-of-sample Sharpe ratio of the accounting-based optimal portfolio falls from 1.71 in table 2 to 0.48 in Table 4, only slightly above the Sharpe ratio of 0.45 for the value-weighted market). The conclusion that we draw from these results is that the importance of firms' accounting characteristics in portfolio optimization crucially depends on whether the investor can short sell, and somewhat but less so this way for price-based characteristics. If she cannot, then the financial statement data items we have studied in this paper would seem to have no economic value to her. Conversely, though, if she can short sell, the results in Table 2 panel $\mathrm{B}$ indicate that financial statement data is economically very valuable in both long and short positions. The juxtaposition of the results from Tables 2 and 4 therefore suggests that the positive alpha earned in the short side of both the accounting-based and price-based hedge portfolios in Table 2 stem from the fact that short-selling allows the investor to take a more negative position in a stock more than just underweighting it.

\subsection{Baseline findings after taking into account alternative proxies for transactions costs}

Our goal in this section is to provide estimates of the impacts that transactions costs have on the findings and inferences we have arrived at thus far in Tables 2-4. In doing so, we emphasize that estimating real-world transactions costs is notoriously difficult, so our posttransaction-cost estimates of performance could be either far too low or far too high.

We employ two of the methods used by Brandt, Santa-Clara and Valkanov (2009). The first is the crude assumption that one-way transactions costs (defined to include the costs of getting into the required positions) are a constant $0.5 \%$ for all firms and over all months. The second allows both time-series and cross-sectional variation by taking the one-way transactions costs $T C_{i t}$ of firm $i$ in month $t$ as:

$$
T C_{i t}=T I M E_{t} \times\left(0.6 \%-0.25 * n o r m_{-} m v e_{i t}\right)
$$

where $T I M E_{t}$ is a monthly trend term that starts at 4.0 in Jan. 1975 and declines linearly until Dec. 2002 to 1.0 after which time it remains at that level, and norm_mve $e_{i t}$ is the firm's market value of equity normalized to lie between zero and one. Equation (12) says that the one-way transactions costs for the largest firm in a given month are $1.0 \%$ of the amount traded (no matter how large or small the amount traded) in Jan. 1975 versus $0.25 \%$ in Dec. 2002 through Dec. 2008, and that transactions costs for the smallest firm are 2.4\% in Jan. 1975 versus $0.6 \%$ in Dec. 2002 through Dec. 2008. BSCV indicate that they choose the parameters in equation (12) to reflect the findings of Keim and Madhavan, 1997, Domowitz, Glen and Madhavan (2001) and Hasbrouck (2006). 
In our implementation, we subtract the transaction costs (dictated by whichever model we are using) from the pre-transactions-costs, out-of-sample monthly portfolio raw returns and then recomputed the statistics in panel B of Tables 2-4. ${ }^{7}$ A subset of these post-transaction-cost statistics is reported in panels A-C of Table 5. Panel A is the after-transactions-cost version of Table 2, where short selling was fully allowed and all firms were included; panel B equates to Table 3, where short selling was again allowed but only the largest 500 firms each month were included in the portfolio optimization; and panel $\mathrm{C}$ parallels Table 4, where all firms are included but short selling is disallowed. For each panel, we report results on the left under constant transactions costs, and on the right under time- and cross-sectionally varying costs.

We note the following key findings in Table 5. First, all of the optimized portfolios create quite large amounts of monthly turnover. Following BSCV (section 2.4), we define monthly turnover in month $t$ as the total sum of the adjustments that need to be made to the portfolio in place at the end of month $t$ relative to where the portfolio needs to be at the beginning of month $t+1$. Thus:

$$
\text { TURNOVER } R_{t}=\sum_{i=1}^{N_{t}}\left|w_{i t}^{T A R}-w_{i t}^{h}\right|
$$

where $w_{i t}^{T A R}$ is the target portfolio (i.e., set of portfolio weights) required at the beginning of month $t+1$ under the optimal portfolio policy $\theta^{\mathrm{T}}$ :

$$
w_{i t}^{T A R}=\bar{w}_{i t}+\theta^{T} x_{i t}
$$

and $w_{i t}^{h}$ is the "hold" set of portfolio weights at the beginning of month $t$ scaled by the relative returns earned over month $t$ :

$$
w_{i t}^{h}=w_{i, t-1} \frac{1+r_{i t}}{1+r_{p t}}
$$

Inspecting panel A of Table 5 shows that the out-of-sample PBC portfolio generates $106 \%$ turnover per month, while the ABC and portfolio generates more than double this at $216 \%$. While such high turnover may seem problematic, it should be kept in mind that the hedge portfolio components of these two optimized portfolios are levered 3.0 and 5.0, respectively. In addition, not only is the time series of value-weighted accounting-based characteristics in the optimal portfolio more variable over time than the price-based characteristics (Table 2, panel B), but the on a firm-specific basis firm size, book-to-market, and momentum together may be more sticky over time than are accruals, change in earnings, and asset growth.

\footnotetext{
${ }^{7}$ Our approach could likely be improved by optimizing the amount of trading given a specified transactions costs model. As BSCV note, the linear specification for the portfolio weight function detailed in equation (3) is not optimal in the presence of transactions costs. Intuitively, the optimal policy will reflect the presence of a boundary surrounding the targeted asset weights such that when the end-of-month actual weight is outside (within) the boundary, it will (will not) be cost-effective to trade (Magill and Constantinides, 1976).
} 
The second noteworthy finding in Table 5 is that the general impact across all three firmcharacteristic portfolio optimizations ( $\mathrm{PBC}, \mathrm{ABC}$ and $\mathrm{PBC}+\mathrm{ABC}$ ) of incorporating transactions costs is to reduce returns (raw, alpha and hedge) and decrease Sharpe ratios and information ratios. For example, the annual Sharpe ratio for the $\mathrm{PBC}+\mathrm{ABC}$ out-of-sample optimized portfolio was 1.89 in the absence of transactions costs (panel B of Table 2), but only 1.63 and 1.12 in the presence of fixed and variable transactions costs, respectively. Third, the performance of the $\mathrm{ABC}$ optimized portfolio declines relatively more than does the performance of the PBC optimized portfolio. The annual Sharpe ratio for the PBC out-of-sample optimized portfolio falls from 1.36 in the absence of transactions costs (panel B of Table 2) to 0.97 after taking out variable transactions costs (panel A of Table 5) - a 28\% decline. In contrast, the ABC portfolio suffers a 58\% drop in its Sharpe ratio, going from 1.71 to 0.77 . Finally, we note that the size of the reductions in Sharpe ratios that we estimate from the variable transactions cost model correlate fairly well with the experience of one seasoned and sophisticated practitioner, namely Grinold (1992, p.38). Grinold notes that "Experience indicates that implementation (of the portfolio optimization process he is proposing in his paper) for a sizable institutional portfolio that includes restrictions on short sales, liquidity, and transaction costs would drop the information ratio (from what Grinold finds to be 1.67) ... into the 0.9 to 0.6 region."

Finally, we note that at least under the variable model, taking transactions costs into account brings the performance of the portfolios optimized over the largest 500 companies, and the portfolios optimized under the constraint of no short sales allowed to within spitting distance of that of the value-weighted market.

\subsection{Performance of accounting-and price-based optimal portfolios in periods of extreme negative shocks}

A prima facie supposition concerning hedge funds is that their investment strategies are deliberately constructed so as to be hedged against market movements. That is, during large market-wide declines, many investors might presume that hedge funds should continue to earn positive returns, especially if they claim to be market neutral. Contrary to this supposition, researchers have found that both in general and during 2008's plunging overall market, hedge funds are/were often far from being hedged (Asness, Krail and Liew, 2001; Agarwal and Naik, 2004; Lo, 2008; Brown, Green and Hand, 2009). In this section we test whether the accountingand price-based optimal portfolios that we study do or do not suffer from a lack of proper hedging by documenting the out-of-sample return performance of the unlevered hedge portfolio portion of accounting- and price-based optimized portfolios in 2008.

In Figure 4 we plot the same cumulative out-of-sample monthly $\mathrm{ABC}, \mathrm{PBC}$ and $\mathrm{PBC}+\mathrm{ABC}$ optimized, pre-transactions-costs hedge portfolio returns as in Figure 3, just limiting the window to the years 2005-2008. We also plot the log of the cumulative value-weighted market return for comparison. Inspection of Figure 4 shows that unlike the precipitous $-38 \%$ drop in the overall market during 2008, the ABC, $\mathrm{PBC}$ and $\mathrm{PBC}+\mathrm{ABC}$ hedge returns ended up $12 \%, 3.4 \%$ and $10 \%$, respectively. Moreover, the accounting-based portfolios (ABC and $\mathrm{PBC}+\mathrm{ABC}$ ) earned remarkably steady positive monthly returns. We infer from these results that accounting-based firm characteristics are economically important to investors over and above their general long-run return properties, because when they are used optimally in portfolio 
construction they yield hedge returns that appear to remain truly hedged even in the face of severe market declines.

Beyond severe downside market risk, an additional threat that some hedge funds have been found to be exposed to is being in a common or "crowded" strategy when sudden and large selling pressure is felt on the stocks in that strategy. The first large realization of this risk was observed for equity hedge funds during the Quant Meltdown of August 6-10, 2007 when a number of quantitative long/short equity hedge funds experienced unprecedented losses. Khandani and Lo $(2007,2008)$ hypothesize that these losses were initiated by the rapid unwinding of one or more big quantitative equity market-neutral portfolios (e.g., as a result of a forced liquidation by a multi-strategy fund or proprietary-trading desk, or perhaps because of a margin call). Khandani and Lo conjecture that these initial losses then put pressure on a broader set of long/short and long-only equity portfolios, particularly those long in book-to-market and short in earnings momentum strategies, thereby leading to further losses by triggering stop/loss and de-leveraging policies at other hedge funds or proprietary trading desks. In this section we therefore seek to determine how well or poorly the accounting- and price-based optimal portfolios that we study performed during the Quant Meltdown. That is, would our accountingand price-based optimal portfolios have provided hedges against crowded-strategy risk?

In Figure 5 we find that an accounting-based optimal hedge portfolio is also resilient in the face of sudden realizations of crowded-strategy risk. Inspection of Figure 4 indicates that while the $\mathrm{ABC}$ hedge portfolio did not earn positive returns over the three-month period JulySept. 2007, it was noticeably less adversely affected than the PBC portfolio in the lead up to and during the week of Aug. 6-10. Over the months of July and August, the accounting-based hedge portfolio earned $-0.2 \%$ as compared to $-3.9 \%$ for the price-based hedge portfolio, and had standard deviations of daily hedge returns of $0.4 \%$ and $1.7 \%$, respectively. We infer from this finding that during this time, markedly fewer hedge funds were in strategies centered on the financial statement variables of accruals, change in earnings, and asset growth than were in strategies centered on firm size, book-to-market, and momentum. As a result, accounting-based hedge returns were less affected by the combination of strategy-crowding and rapid, intense deleveraging that hit hedge funds during the Quant Meltdown.

\section{Caveats}

As in any academic study, it is essential to itemize major caveats that we feel should be highlighted to a reader. In our minds, two main caveats apply. First, there is no guarantee that the results we find will necessarily continue into the future. Although we, like BSCV, take pains to conduct out-of-sample tests, our inferences are likely contaminated by snooping bias. That is, our choice of which illustrative firm characteristics to use is affected by their having been found by prior researchers to be predictive of future returns. Second, we emphasize that substantial uncertainty exists as to whether our transactions costs models are accurate. 


\section{Conclusions}

In this paper, we have studied the economic importance of accounting information using the non-standard definition that accounting information is important when it can be used by sophisticated investors to extract from financial statements when maximizing their expected utility from holding a portfolio of U.S. equities. We estimate this value by implementing the elegant parametric portfolio policy (PPP) method of Brandt, Santa-Clara and Valkanov (2009) that models portfolio weights as a linear function of firm-specific characteristics. The illustrative characteristics we employ are three accounting-based financial statement measures-accruals, change in earnings, and asset growth. We compare and contrast the out-of-sample annualized returns generated by the portfolio that optimally extracts the accounting-based characteristics with the equivalent returns generated from three illustrative stock-price-based firm characteristics - firm size, book-to-market, and momentum.

We find that on a pre-transactions cost basis, the optimal accounting-based short-sellingallowed portfolio yields an annual information ratio of 1.9 as compared to 1.5 for the standard price-based characteristics of firm size, book-to-market, and momentum. These information ratios decline when transactions costs are taken into account, when the analysis is limited to only the largest 500 firms, and when short-sales are disallowed.

We also find that the pre-transactions-costs delevered hedge portion of the accountingbased optimal portfolio performed very well during two recent shocks. First, it earned $12 \%$ during 2008 as compared to $3.4 \%$ for the price-based hedge and $-38 \%$ for the value-weighted market. Second, it fared far better than the price-based hedge during the Quant Meltdown of August, 2007. These robust performances suggest that accounting information may be especially valuable to investors because it appears to be economically important in portfolio optimization in both "regular" and "extreme" stock market environments. 


\section{Figure 1: PPP method implementation timeline}

This figure portrays the timeline with respect to when accounting-based and price-based firm characteristics are measured. For purposes of illustration the firm has a calendar fiscal year.

Variables are as defined in Table 1.

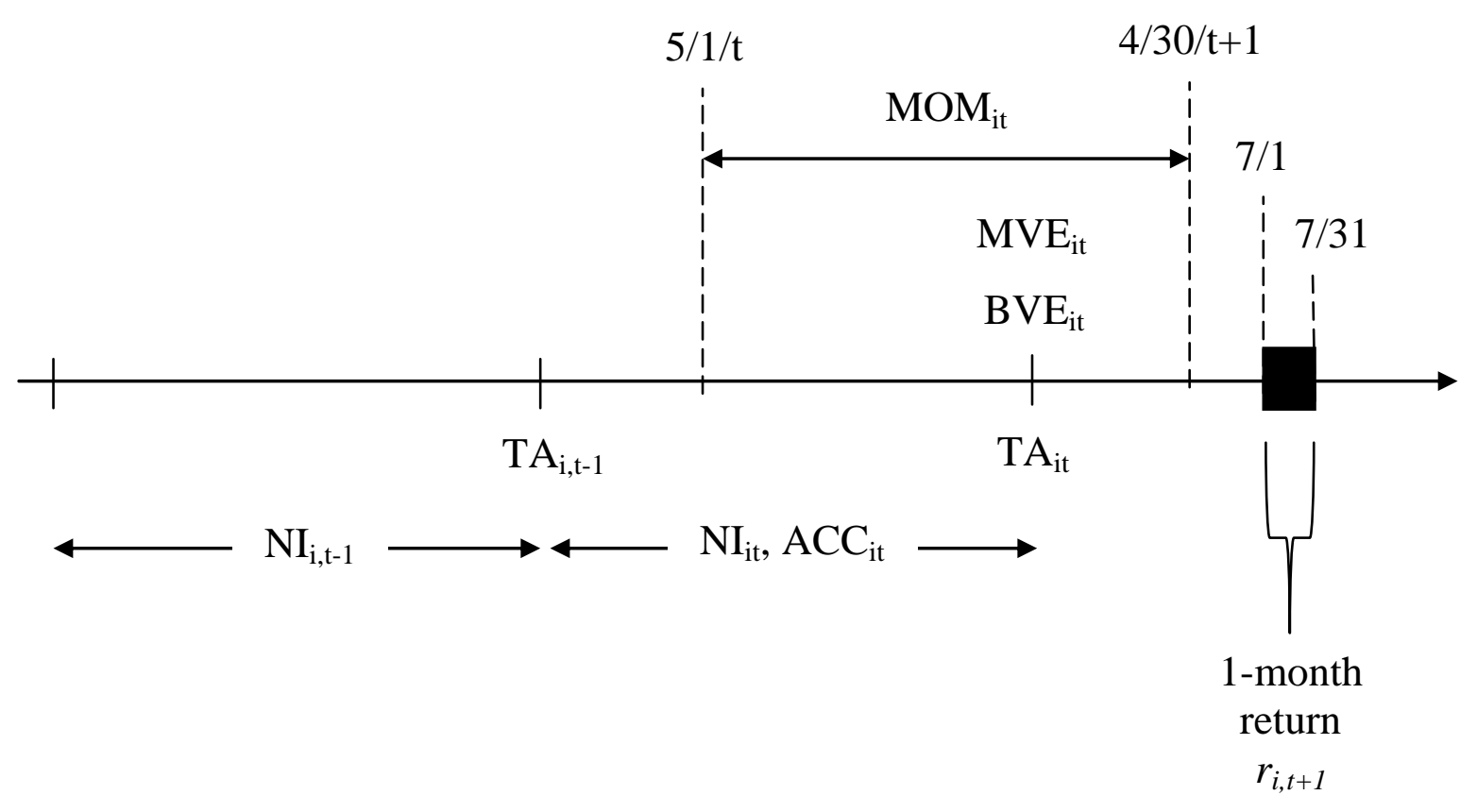




\section{Figure 2: Time-series of annual optimal portfolio policy parameter estimates and monthly value-weighted characteristics of firms in the optimal portfolio}

This figure displays the time-series of annual optimal portfolio policy parameter estimates applied to firms' characteristics, and the monthly value-weighted firm characteristics applicable to the out-ofsample section of Table 2 where the Brandt, Santa-Clara and Valkanov (2009) method is applied to both accounting-based firm characteristics (ABC) and stock-price-based firm characteristics (PBC).

The time window consists of the 408 months between Jan. 1975-Dec. 2008.

Panel A: Annual optimal portfolio policy parameters

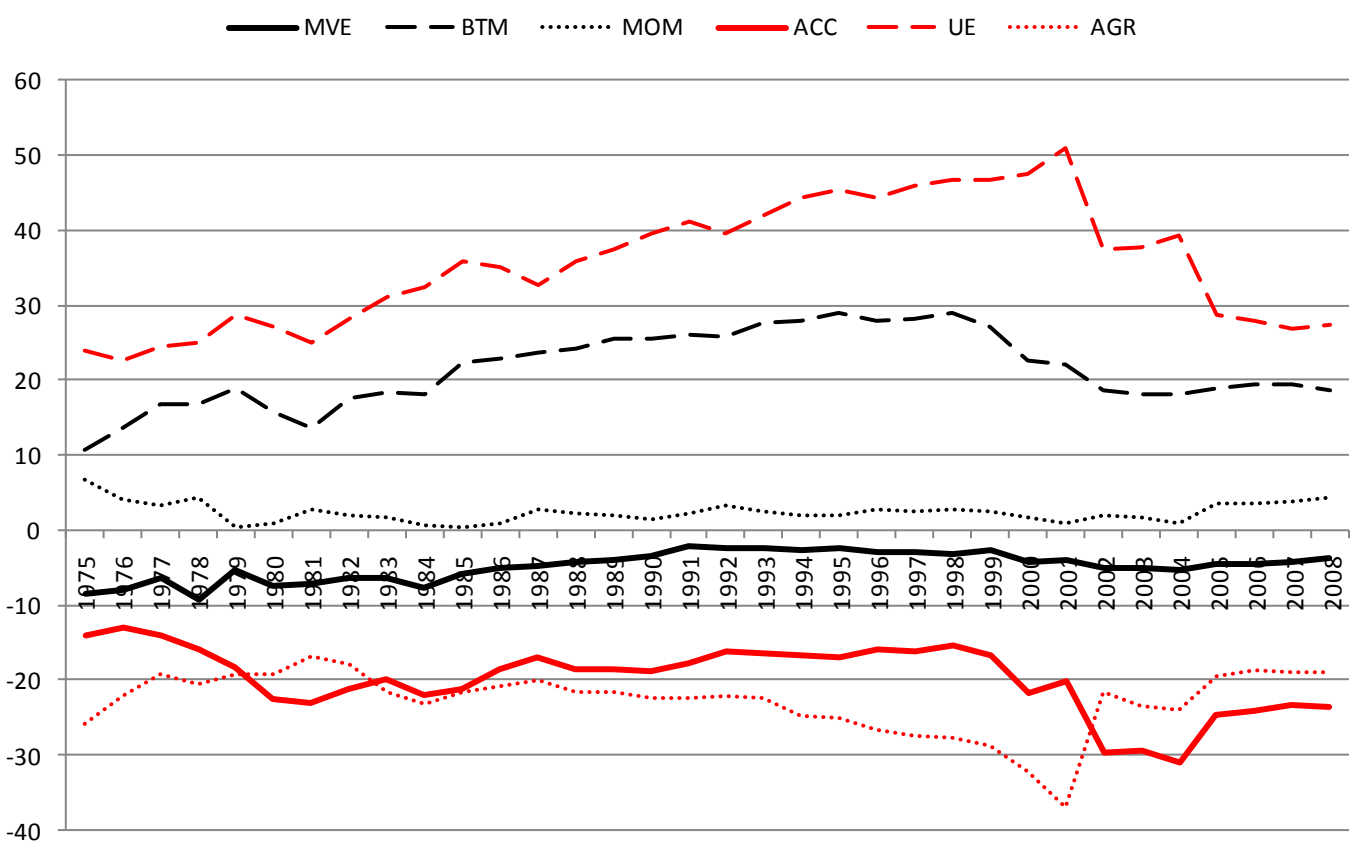

Panel B: Monthly value-weighted firm characteristics

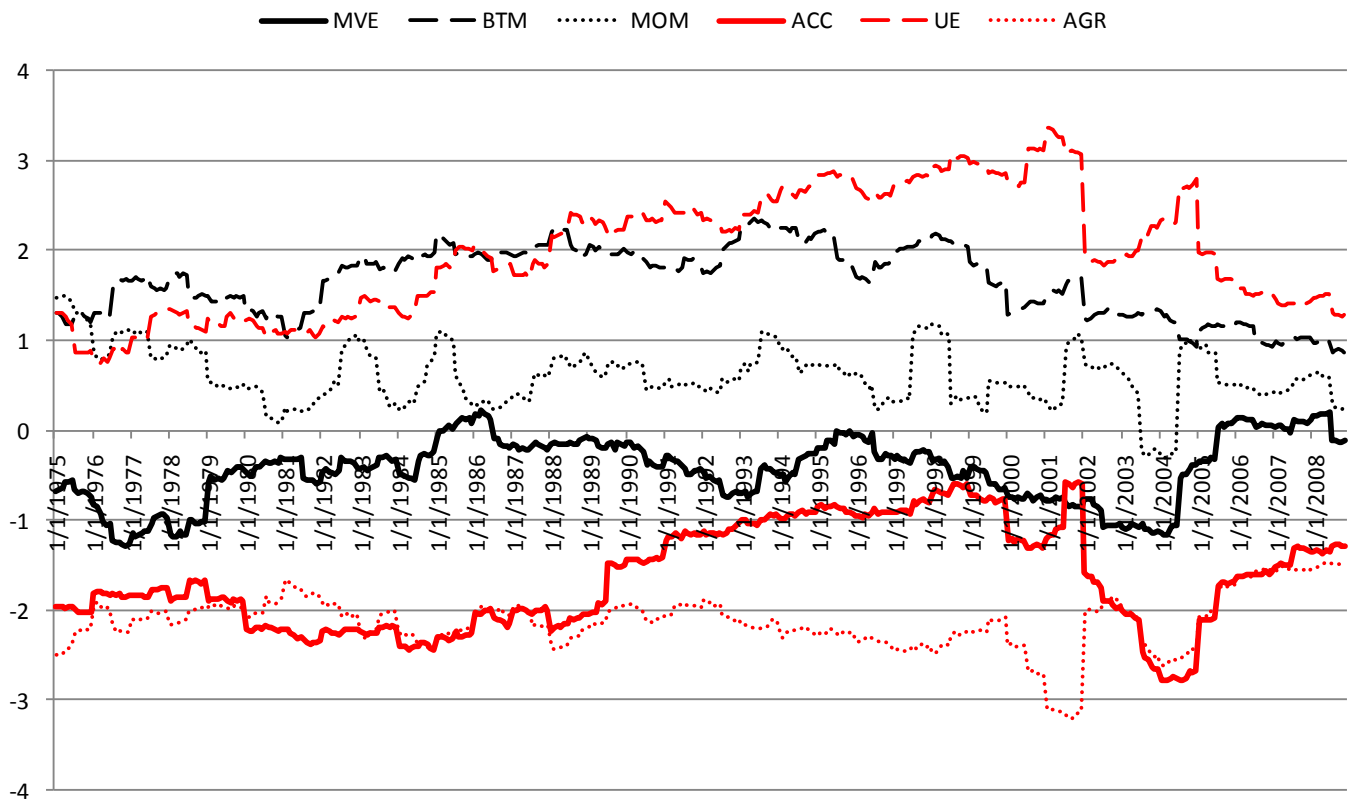




\section{Figure 3: Monthly performance of the unlevered hedge returns from using BSCV's PPP method}

This figure plots the log of the cumulative out-of-sample monthly unlevered dollar-neutral raw hedge returns from the PPP method of Brandt, Santa-Clara and Valkanov (2009) to optimize an investor's portfolio toward accounting-based firm characteristics (ABC_ln_cum_hedge_r), price-based characteristics (PBC_ln_cum_hedge_r), and accounting + price-based characteristics (PBC+ABC_ln_cum_hedge_r). The log cumulative monthly returns to the value-weighted market (ln_cum_VW_r) is also plotted for comparison. Period is Jan. $1975-$ Dec. 2008.

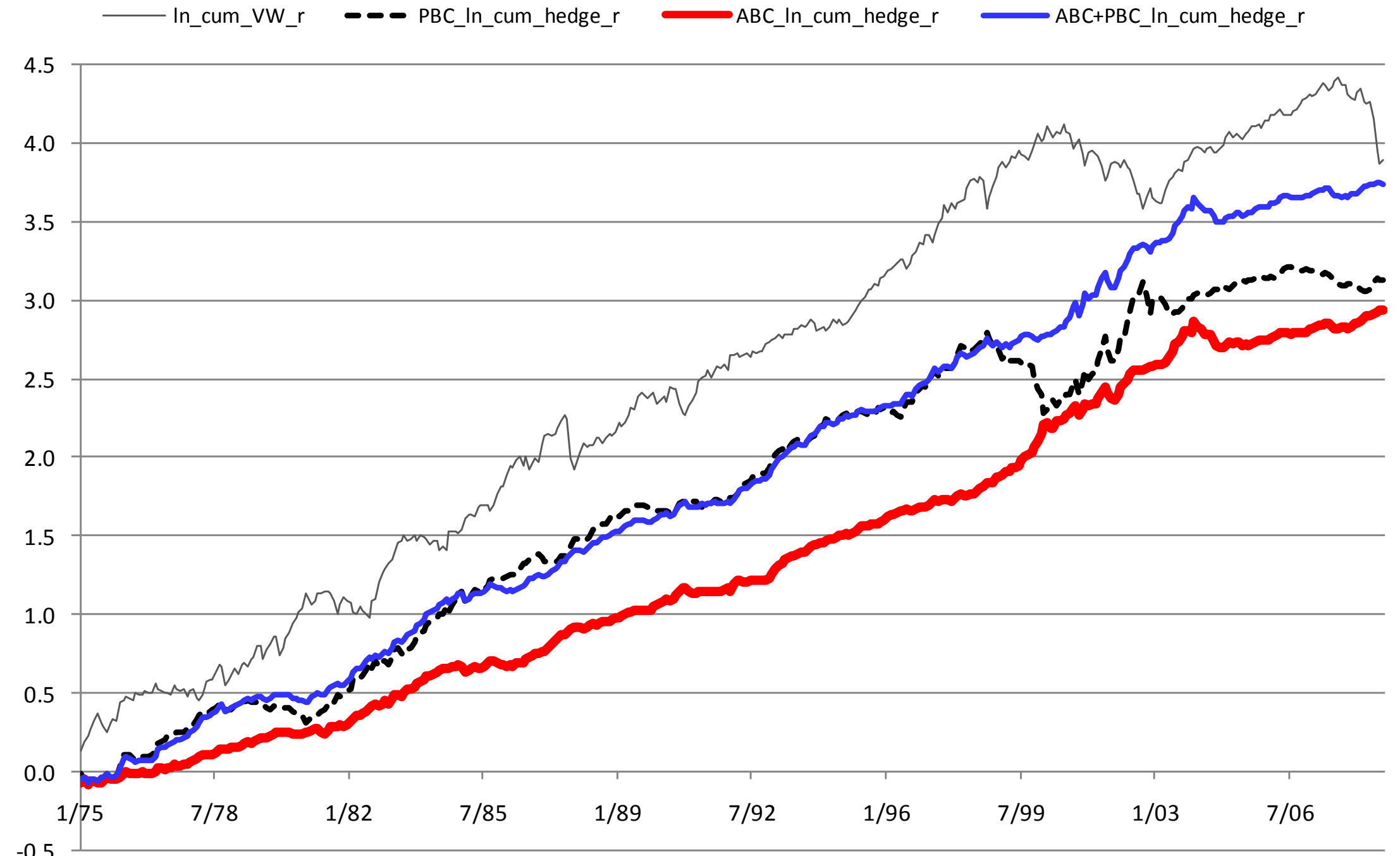




\section{Figure 4: Performance of the unlevered hedge returns from using BSCV's PPP method in 2008}

This figure plots the log of the cumulative out-of-sample monthly unlevered dollar-neutral raw hedge returns from the PPP method of Brandt, Santa-Clara and Valkanov (2009) to optimize an investor's portfolio toward accounting-based firm characteristics (ABC_ln_cum_hedge_r), price-based characteristics (PBC_ln_cum_hedge_r), and accounting + price-based characteristics (PBC+ABC_ln_cum_hedge_r). The log of the

cumulative monthly returns to the value-weighted market (ln_cum_VW_r) is also plotted for comparison. Period is Jan. 2005 - Dec. 2008.
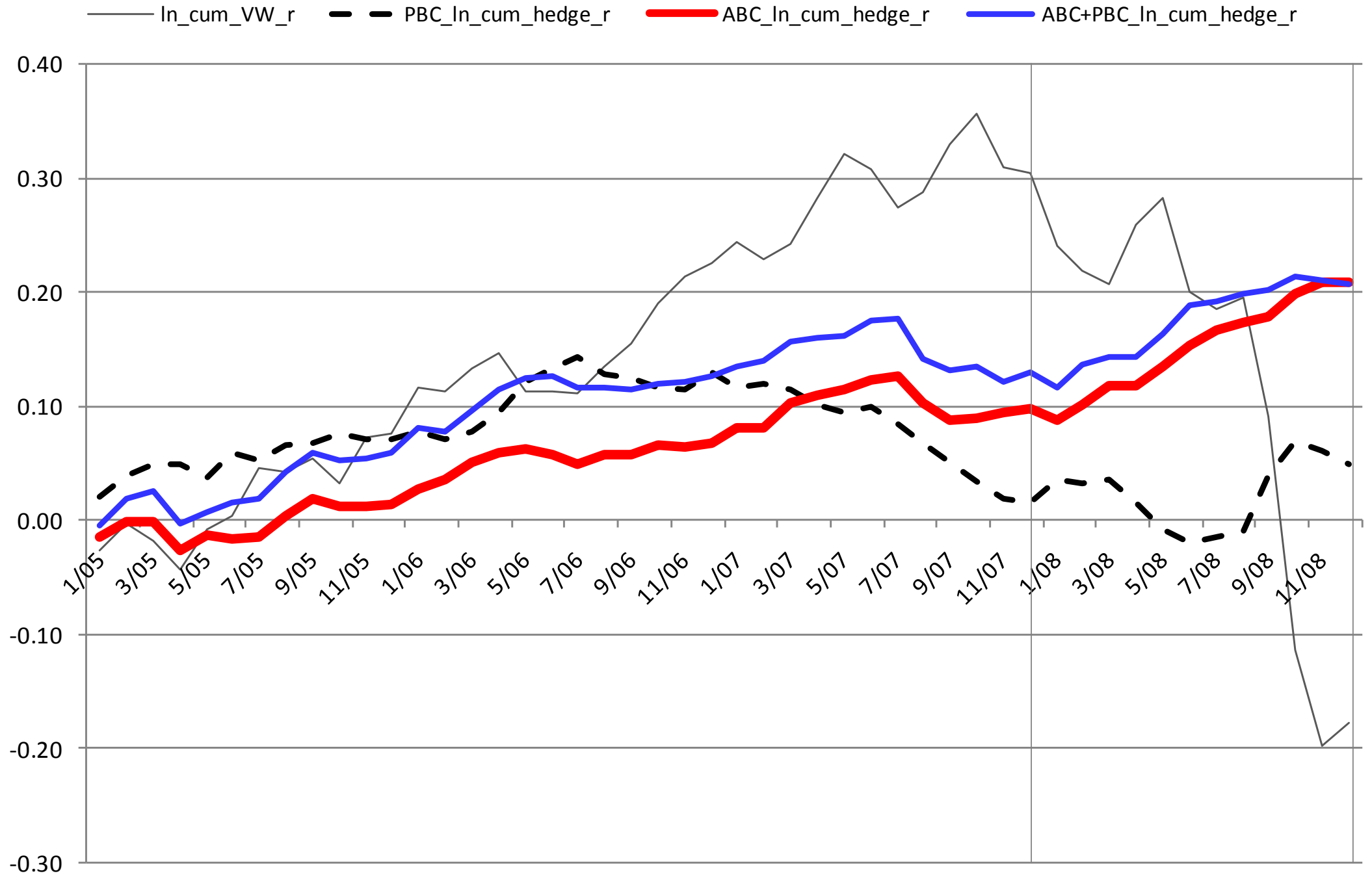


\section{Figure 5: Performance of the unlevered hedge returns from using BSCV's PPP method during the Quant Meltdown}

This figure plots the log of the cumulative out-of-sample monthly unlevered dollar-neutral raw hedge returns from the PPP method of Brandt, Santa-Clara and Valkanov (2009) to optimize an investor's portfolio toward accounting-based firm characteristics (ABC_ln_cum_hedge_r), price-based characteristics (PBC_ln_cum_hedge_r), and accounting + price-based characteristics (PBC+ABC_ln_cum_hedge_r). The log of the cumulative monthly returns to the value-weighted market (ln_cum_VW_r) is also plotted for comparison.

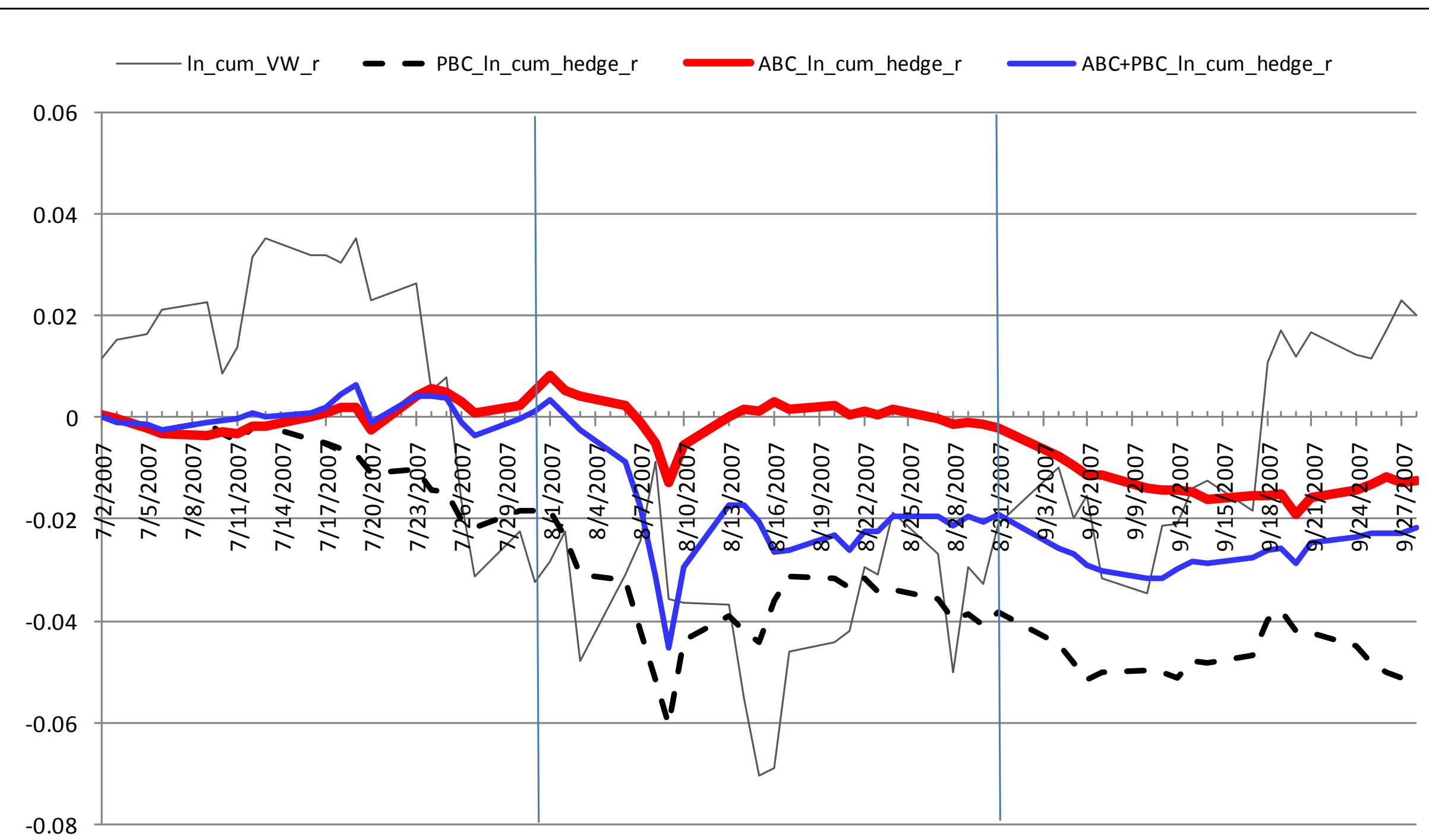




\section{Table 1: Variable definitions and sample selection criteria}

This table reports the definitions of data items employed in the estimations (panel A) and the restrictions imposed in arriving at the sample used to estimate the parameters

in our application of Brandt, Santa-Clara and Valkanov's (2009) linear parametric portfolio policy method (panel B).

Panel A: Definitions of accounting-based firm characteristics (ABCs) and price-based firm characteristics (FBCs) used in the BSCV portfolio optimizations

- Firm size (MVE) = fiscal year end market value of common equity.

- Book-to-market (BTM) = book value of common equity / MVE.

- Momentum $(\mathrm{MOM})=$ cumulative raw return for the 12 months ending 4 months after the most recent fiscal year end.

- Accruals $(\mathrm{ACC})=$ net income - operating cash flow scaled by average total assets if operating cash flow is available, otherwise $\mathrm{ACC}=\Delta$ current assets $-\Delta$ cash $-\Delta$ current liabilities $-\Delta$ debt in current liabilities $-\Delta$ taxes payable - depreciation, all scaled by average total assets. If any of the aforementioned components is missing we set it to zero.

- Change in earnings (UE) = change in net income scaled by average total assets.

- Asset growth $(\mathrm{AGR})=\ln [1+$ total assets $]-\ln [1+$ lagged total assets $]$.

\section{Panel B: Sample selection criteria and data restrictions}

Initial set of unrestricted monthly stock returns

\begin{tabular}{cr} 
\# monthly obs. & Percent \\
\hline $2,642,298$ & $100 \%$ \\
$2,392,504$ & $91 \%$ \\
& \\
$2,168,745$ & $82 \%$ \\
$1,735,192$ & $66 \%$ \\
\hline
\end{tabular}

After requiring sufficient data to compute a firm's book-to-market, market capitzlixation, and 12-month stock return momentum

After also requiring sufficient data to compute a firm's accruals, change in earnings, and asset growth

After deleting the smallest $20 \%$ of stocks

\section{Number of observations by year}

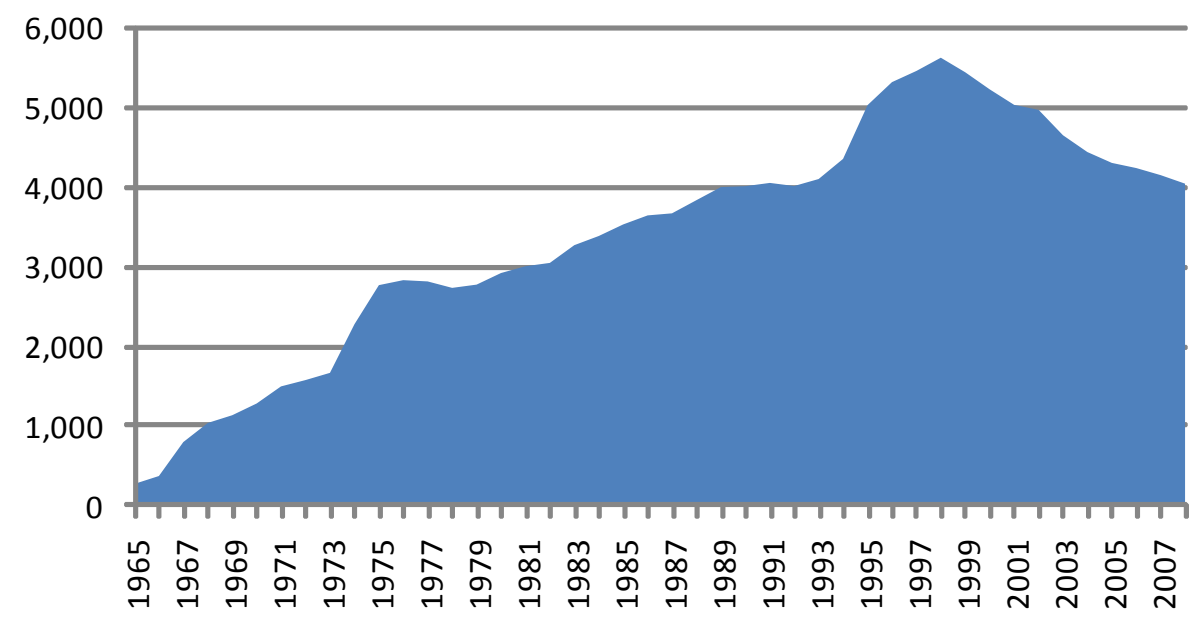


Table 2: Brandt, Santa-Clara and Valkanov's (BSCV, 2009) linear parametric portfolio policy (PPP) method applied to stock-price-based and accounting-based firm characteristics

This table reports the results of estimating the coefficients of the linear portfolio weight function specified in equation (3) with respect to three stock-price-based firm characteristics (market capitalization, book-to-market, momentum) and three accountingbased firm characteristics (accruals, unexpected earnings, asset growth). The optimization problem in equation (10) uses a power utility function with relative risk aversion of 5. Data restrictions and variable definitions are given in Table 1.

Panel A: Parameter estimates, average portfolio weights, and average firm characteristics in the optimal portfolio

\begin{tabular}{|c|c|c|c|c|c|c|c|}
\hline & & \multicolumn{3}{|c|}{$\begin{array}{l}\text { PPP in-sample } \\
\text { Estimation period is Jan. } 1975 \text { - Dec. } 2008\end{array}$} & \multicolumn{3}{|c|}{$\begin{array}{c}\text { PPP out-of-sample } \\
\text { Monthly over Jan. } 1975 \text { - Dec. } 2008\end{array}$} \\
\hline & VW market & PBCs & $\mathrm{ABCs}$ & $\mathrm{PBCs}+\mathrm{ABCs}$ & PBCs & $\mathrm{ABCs}$ & $\mathrm{PBCs}+\mathrm{ABCs}$ \\
\hline$\theta_{\mathrm{me}}$ & & -4.6 & & -1.8 & -3.0 & & -4.9 \\
\hline $\operatorname{se}\left[\theta_{\mathrm{me}}\right]$ & & [2.6] & & [3.1] & [3.4] & & [4.1] \\
\hline$\theta_{\mathrm{btm}}$ & & 18.9 & & 20.5 & 22.8 & & 21.4 \\
\hline $\operatorname{se}\left[\theta_{\mathrm{btm}}\right]$ & & [3.0] & & [4.7] & {$[4.3]$} & & {$[6.3]$} \\
\hline$\theta_{\text {mom }}$ & & 7.6 & & 7.4 & 11.4 & & 2.4 \\
\hline $\operatorname{se}\left[\theta_{\mathrm{mom}}\right]$ & & [3.1] & & {$[4.5]$} & [3.9] & & [5.1] \\
\hline$\theta_{\text {acc }}$ & & & -9.8 & -26.6 & & -16.7 & -19.8 \\
\hline $\operatorname{se}\left[\theta_{\text {acc }}\right]$ & & & [6.5] & {$[7.9]$} & & {$[9.3]$} & [11.6] \\
\hline & & & 29.6 & 24.2 & & 29.7 & 35.4 \\
\hline $\operatorname{se}\left[\theta_{\mathrm{ue}}\right]$ & & & [6.8] & {$[9.3]$} & & [8.4] & [10.6] \\
\hline$\theta_{\text {agr }}$ & & & -39.2 & -21.7 & & -33.0 & -22.9 \\
\hline $\operatorname{se}\left[\theta_{\mathrm{agr}}\right]$ & & & {$[6.0]$} & {$[8.0]$} & & {$[9.4]$} & [11.0] \\
\hline Avg. $\left|w_{i}\right| \times 100$ & 0.03 & 0.14 & 0.28 & 0.30 & 0.16 & 0.27 & 0.29 \\
\hline Avg. $\max w_{i} \times 100$ & 3.2 & 3.0 & 3.3 & 3.2 & 3.0 & 3.3 & 3.1 \\
\hline Avg. $\min w_{i} \times 100$ & 0.0 & -0.4 & -1.0 & -1.2 & -0.5 & -1.0 & -1.2 \\
\hline Avg. $\Sigma w_{i} I\left(w_{i}<0\right)$ & 0.0 & -2.1 & -4.8 & -5.0 & -2.6 & -4.7 & -5.1 \\
\hline $\operatorname{Avg} \Sigma \Sigma I\left(w_{i} \leq 0\right) / N_{t}$ & 0.0 & 0.45 & 0.48 & 0.48 & 0.45 & 0.48 & 0.48 \\
\hline Avg. weighted MVE & 0.41 & -0.29 & & -0.18 & -0.20 & & -0.44 \\
\hline Avg. weighted BTM & -0.12 & 1.48 & & 1.61 & 1.73 & & 1.65 \\
\hline Avg. weighted MOM & 0.04 & 0.45 & & 0.79 & 0.73 & & 0.61 \\
\hline Avg. weighted ACC & & & -1.32 & -2.41 & & -1.71 & -1.65 \\
\hline Avg. weighted UE & & & 1.59 & 1.07 & & 1.66 & 1.97 \\
\hline Avg. weighted AGR & & & -2.91 & -2.32 & & -2.58 & -2.13 \\
\hline \# monthly obs & & 408 & 408 & 408 & 408 & 408 & 408 \\
\hline
\end{tabular}


Table 2 (continued)

Panel B: Descriptive statistics on the returns generated by the optimal portfolio

\begin{tabular}{|c|c|c|c|c|c|c|c|}
\hline \multirow{2}{*}{$\begin{array}{l}\text { Statistics for } \\
\text { annualized returns on } \\
\text { the optimal portfolio }\end{array}$} & \multirow[t]{2}{*}{ VW market } & \multicolumn{3}{|c|}{$\begin{array}{l}\text { PPP in-sample } \\
\text { Estimation period is Jan. } 1975 \text { - Dec. } 2008\end{array}$} & \multicolumn{3}{|c|}{$\begin{array}{c}\text { PPP out-of-sample } \\
\text { Monthly over Jan. } 1975 \text { - Dec. } 2008\end{array}$} \\
\hline & & PBCs & $\mathrm{ABCs}$ & $\mathrm{PBCs}+\mathrm{ABCs}$ & PBCs & $\mathrm{ABCs}$ & $\mathrm{PBCs}+\mathrm{ABCs}$ \\
\hline Certainty equivalent $r$ & $6.2 \%$ & $24.8 \%$ & $38.5 \%$ & $48.4 \%$ & $23.5 \%$ & $35.0 \%$ & $43.6 \%$ \\
\hline Mean $r$ & $12.7 \%$ & $37.5 \%$ & $59.4 \%$ & $74.7 \%$ & $42.1 \%$ & $58.0 \%$ & $75.5 \%$ \\
\hline$\sigma(r)$ & $15.4 \%$ & $22.1 \%$ & $28.7 \%$ & $31.7 \%$ & $26.7 \%$ & $30.5 \%$ & $37.0 \%$ \\
\hline Sharpe ratio & 0.45 & 1.44 & 1.87 & 2.18 & 1.36 & 1.71 & 1.89 \\
\hline$\alpha$ & & $34.3 \%$ & $52.8 \%$ & $73.0 \%$ & $40.5 \%$ & $50.6 \%$ & $74.6 \%$ \\
\hline$\beta$ & & 0.25 & 0.52 & 0.13 & 0.12 & 0.59 & 0.07 \\
\hline$\sigma(\varepsilon)$ & & $21.8 \%$ & $27.5 \%$ & $31.6 \%$ & $26.7 \%$ & $29.2 \%$ & $37.0 \%$ \\
\hline Information ratio & & 1.58 & 1.92 & 2.31 & 1.52 & 1.74 & 2.02 \\
\hline Optimized mean $r=\mathrm{A}$ & $12.7 \%$ & $37.5 \%$ & $59.4 \%$ & $74.7 \%$ & $42.1 \%$ & $58.0 \%$ & $75.5 \%$ \\
\hline Mkt $r=\mathrm{B}$ & $12.7 \%$ & $12.7 \%$ & $12.7 \%$ & $12.7 \%$ & $12.7 \%$ & $12.7 \%$ & $12.7 \%$ \\
\hline Managed $r l e v=\mathrm{A}-\mathrm{B}$ & $0.0 \%$ & $24.8 \%$ & $46.7 \%$ & $62.0 \%$ & $29.4 \%$ & $45.3 \%$ & $62.8 \%$ \\
\hline Leverage of rlev & & 2.54 & 5.15 & 5.34 & 3.00 & 5.02 & 5.49 \\
\hline Hedge long side $r$ & & $19.6 \%$ & $18.5 \%$ & $20.2 \%$ & $19.5 \%$ & $18.5 \%$ & $19.9 \%$ \\
\hline Hedge short side $r$ & & $-9.9 \%$ & $-9.4 \%$ & $-8.6 \%$ & $-9.9 \%$ & $-9.7 \%$ & $-8.6 \%$ \\
\hline Hedge $r$ & & $9.7 \%$ & $9.1 \%$ & $11.6 \%$ & $9.7 \%$ & $8.8 \%$ & $11.3 \%$ \\
\hline Hedge $\sigma$ & & $9.5 \%$ & $5.5 \%$ & $6.4 \%$ & $8.1 \%$ & $4.6 \%$ & $5.9 \%$ \\
\hline Hedge t-stat. & & 6.0 & 9.6 & 10.6 & 7.0 & 11.2 & 11.2 \\
\hline Hedge $\alpha$ & & $13.4 \%$ & $10.3 \%$ & $13.7 \%$ & $13.4 \%$ & $9.8 \%$ & $13.2 \%$ \\
\hline Hedge $\beta$ & & -0.29 & -0.09 & -0.17 & -0.29 & -0.08 & -0.16 \\
\hline Hedge $\sigma(\varepsilon)$ & & $8.3 \%$ & $5.3 \%$ & $5.9 \%$ & $8.7 \%$ & $5.2 \%$ & $6.2 \%$ \\
\hline Hedge IR & & 1.61 & 1.94 & 2.32 & 1.54 & 1.88 & 2.13 \\
\hline Hedge long side $\alpha$ & & $7.5 \%$ & $4.4 \%$ & $6.7 \%$ & $7.4 \%$ & $4.3 \%$ & $6.3 \%$ \\
\hline Hedge long side $\beta$ & & 0.95 & 1.11 & 1.06 & 0.96 & 1.11 & 1.07 \\
\hline Hedge long side $\sigma(\varepsilon)$ & & $10.5 \%$ & $10.8 \%$ & $10.5 \%$ & $10.0 \%$ & $10.7 \%$ & $10.9 \%$ \\
\hline Hedge short side $\alpha$ & & $5.9 \%$ & $5.9 \%$ & $7.0 \%$ & $6.0 \%$ & $5.5 \%$ & $6.9 \%$ \\
\hline Hedge short side $\beta$ & & -1.25 & -1.20 & -1.23 & -1.25 & -1.19 & -1.23 \\
\hline Hedge short side $\sigma(\mathrm{e})$ & & $9.9 \%$ & $10.2 \%$ & $10.3 \%$ & $10.9 \%$ & $10.2 \%$ & $10.4 \%$ \\
\hline \# monthly obs & & 408 & 408 & 408 & 408 & 408 & 408 \\
\hline
\end{tabular}

Notes:

1. Following BSCV, we define annualized returns as the sum of calendar monthly returns.

2. Betas $(\beta)$ are calculated against the VW market. 
Table 3: Brandt, Santa-Clara and Valkanov's (BSCV, 2009) linear parametric portfolio policy (PPP) applied to stock-price-based and accounting-based firm characteristics: Largest 500 market capitalization firms only

This table reports the results of estimating the coefficients of the linear portfolio weight function specified in equation (3) with respect to three stock-price-based firm characteristics (PBCs: market capitalization, book-to-market, momentum) and three accounting-based firm characteristics (ABCs: accruals, unexpected earnings, asset growth). The optimization problem in equation (10) uses a power utility function with relative risk aversion of 5. Data restrictions and variable definitions are given in Table 1.

Relative to Table 2, this table restricts the set of investable stocks to the largest 500 firms by market capitalization.

Panel A: Parameter estimates, average portfolio weights, and average firm characteristics in the optimal portfolio

\begin{tabular}{|c|c|c|c|c|c|c|c|}
\hline & \multirow[b]{2}{*}{ VW market } & \multicolumn{3}{|c|}{$\begin{array}{l}\text { PPP in-sample } \\
\text { Estimation period is Jan. } 1975 \text { - Dec. } 2008\end{array}$} & \multicolumn{3}{|c|}{$\begin{array}{c}\text { PPP out-of-sample } \\
\text { Monthly over Jan. } 1975 \text { - Dec. } 2008\end{array}$} \\
\hline & & PBCs & $\mathrm{ABCs}$ & $\mathrm{PBCs}+\mathrm{ABCs}$ & PBCs & $\mathrm{ABCs}$ & $\mathrm{PBCs}+\mathrm{ABCs}$ \\
\hline$\theta_{\mathrm{me}}$ & & 1.6 & & 0.4 & 1.3 & & 1.8 \\
\hline $\operatorname{se}\left[\theta_{\mathrm{me}}\right]$ & & [0.9] & & {$[0.9]$} & [1.2] & & [1.6] \\
\hline$\theta_{\mathrm{btm}}$ & & 6.3 & & 1.1 & 7.3 & & 4.3 \\
\hline $\operatorname{se}\left[\theta_{\mathrm{btm}}\right]$ & & [2.4] & & [3.7] & [3.1] & & [3.9] \\
\hline$\theta_{\mathrm{mom}}$ & & -2.0 & & -2.5 & 2.6 & & 1.2 \\
\hline $\operatorname{se}\left[\theta_{\mathrm{mom}}\right]$ & & [1.9] & & {$[2.5]$} & [3.2] & & [3.7] \\
\hline & & & -12.9 & -12.4 & & -5.5 & -1.0 \\
\hline $\operatorname{se}\left[\theta_{\text {acc }}\right]$ & & & {$[4.7]$} & {$[4.4]$} & & {$[5.3]$} & {$[7.4]$} \\
\hline & & & 4.0 & 9.2 & & 12.4 & 16.6 \\
\hline $\operatorname{se}\left[\theta_{\text {ue }}\right]$ & & & {$[4.7]$} & {$[5.6]$} & & {$[6.6]$} & {$[7.8]$} \\
\hline$\theta_{\text {agr }}$ & & & -13.5 & -14.0 & & -20.3 & -23.3 \\
\hline $\operatorname{se}\left[\theta_{\text {agr }}\right]$ & & & [3.3] & {$[4.8]$} & & {$[6.2]$} & {$[8.7]$} \\
\hline Avg. $\left|w_{i}\right| \times 100$ & 0.20 & 0.37 & 0.85 & 0.86 & 0.41 & 0.91 & 1.06 \\
\hline Avg. $\max w_{i} \times 100$ & 4.1 & 3.9 & 4.6 & 4.7 & 3.9 & 4.6 & 4.8 \\
\hline Avg. $\min w_{i} \times 100$ & 0.0 & -0.6 & -2.3 & -2.6 & -0.8 & -2.8 & -3.5 \\
\hline Avg. $\Sigma w_{i} I\left(w_{i}<0\right)$ & 0.0 & -0.4 & -1.5 & -1.5 & -0.6 & -1.8 & -2.1 \\
\hline Avg. $\Sigma I\left(w_{i} \leq 0\right) / N_{t}$ & 0.0 & 0.34 & 0.40 & 0.40 & 0.38 & 0.44 & 0.43 \\
\hline Avg. weighted MVE & 0.47 & 0.51 & & 0.59 & 0.43 & & 0.52 \\
\hline Avg. weighted BTM & -0.14 & 0.27 & & -0.02 & 0.34 & & 0.22 \\
\hline Avg. weighted MOM & 0.04 & -0.12 & & -0.04 & 0.16 & & 0.22 \\
\hline Avg. weighted ACC & & & -0.92 & -0.86 & & -0.52 & -0.30 \\
\hline Avg. weighted UE & & & -0.05 & 0.19 & & 0.35 & 0.50 \\
\hline Avg. weighted AGR & & & -0.88 & -0.85 & & -1.04 & -1.19 \\
\hline \# monthly obs & & 408 & 408 & 408 & 408 & 408 & 408 \\
\hline
\end{tabular}


Table 3 (continued)

Panel B: Descriptive statistics on the returns generated by the optimal portfolio

\begin{tabular}{|c|c|c|c|c|c|c|c|}
\hline \multirow{2}{*}{$\begin{array}{c}\text { Statistics for } \\
\text { annualized returns on } \\
\text { the optimal portfolio }\end{array}$} & \multirow[t]{2}{*}{ VW market } & \multicolumn{3}{|c|}{$\begin{array}{l}\text { PPP in-sample } \\
\text { Estimation period is Jan. } 1975 \text { - Dec. } 2008\end{array}$} & \multicolumn{3}{|c|}{$\begin{array}{c}\text { PPP out-of-sample } \\
\text { Monthly over Jan. } 1975 \text { - Dec. } 2008\end{array}$} \\
\hline & & PBCs & $\mathrm{ABCs}$ & $\mathrm{PBCs}+\mathrm{ABCs}$ & PBCs & $\mathrm{ABCs}$ & $\mathrm{PBCs}+\mathrm{ABCs}$ \\
\hline Certainty equivalent $r$ & $5.9 \%$ & $9.2 \%$ & $17.6 \%$ & $18.5 \%$ & $8.8 \%$ & $14.8 \%$ & $15.3 \%$ \\
\hline Mean $r$ & $12.0 \%$ & $17.4 \%$ & $31.0 \%$ & $32.6 \%$ & $14.4 \%$ & $27.0 \%$ & $32.4 \%$ \\
\hline$\sigma(r)$ & $15.2 \%$ & $17.6 \%$ & $22.0 \%$ & $22.9 \%$ & $20.2 \%$ & $22.6 \%$ & $30.7 \%$ \\
\hline Sharpe ratio & 0.42 & 0.67 & 1.15 & 1.18 & 0.43 & 0.95 & 0.87 \\
\hline$\alpha$ & & $6.5 \%$ & $20.9 \%$ & $22.0 \%$ & $4.3 \%$ & $20.8 \%$ & $24.2 \%$ \\
\hline$\beta$ & & 0.91 & 0.84 & 0.88 & 0.84 & 0.52 & 0.68 \\
\hline$\sigma(\varepsilon)$ & & $10.9 \%$ & $18.0 \%$ & $18.6 \%$ & $15.7 \%$ & $21.2 \%$ & $28.9 \%$ \\
\hline Information ratio & & 0.60 & 1.16 & 1.19 & 0.27 & 0.98 & 0.84 \\
\hline Optimized mean $r=\mathrm{A}$ & $12.0 \%$ & $17.4 \%$ & $31.0 \%$ & $32.6 \%$ & $14.4 \%$ & $27.0 \%$ & $32.4 \%$ \\
\hline Mkt $r=\mathrm{B}$ & $12.0 \%$ & $12.0 \%$ & $12.0 \%$ & $12.0 \%$ & $12.0 \%$ & $12.0 \%$ & $12.0 \%$ \\
\hline Managed $r l e v=\mathrm{A}-\mathrm{B}$ & $0.0 \%$ & $5.4 \%$ & $19.0 \%$ & $20.6 \%$ & $2.4 \%$ & $15.0 \%$ & $20.4 \%$ \\
\hline Leverage of rlev & & 0.77 & 2.03 & 2.11 & 0.82 & 2.10 & 2.58 \\
\hline Hedge long side $r$ & & $15.0 \%$ & $16.3 \%$ & $16.3 \%$ & $14.9 \%$ & $16.2 \%$ & $16.1 \%$ \\
\hline Hedge short side $r$ & & $-9.2 \%$ & $-7.5 \%$ & $-7.1 \%$ & $-13.6 \%$ & $-9.2 \%$ & $-8.2 \%$ \\
\hline Hedge $r$ & & $5.7 \%$ & $8.8 \%$ & $9.2 \%$ & $1.3 \%$ & $7.0 \%$ & $7.9 \%$ \\
\hline Hedge $\sigma$ & & $23.9 \%$ & $10.5 \%$ & $10.2 \%$ & $19.9 \%$ & $9.2 \%$ & $10.3 \%$ \\
\hline Hedge t-stat. & & 1.4 & 4.9 & 5.3 & 0.4 & 4.4 & 4.5 \\
\hline Hedge $\alpha$ & & $11.4 \%$ & $11.0 \%$ & $10.9 \%$ & $11.0 \%$ & $10.8 \%$ & $11.2 \%$ \\
\hline Hedge $\beta$ & & -0.47 & -0.18 & -0.15 & -0.80 & -0.32 & -0.28 \\
\hline Hedge $\sigma(\varepsilon)$ & & $22.8 \%$ & $10.2 \%$ & $10.0 \%$ & $29.5 \%$ & $11.4 \%$ & $13.6 \%$ \\
\hline Hedge IR & & 0.50 & 1.08 & 1.09 & 0.37 & 0.95 & 0.82 \\
\hline Hedge long side $\alpha$ & & $2.8 \%$ & $4.1 \%$ & $4.2 \%$ & $3.0 \%$ & $4.3 \%$ & $4.3 \%$ \\
\hline Hedge long side $\beta$ & & 1.01 & 1.01 & 1.01 & 0.99 & 0.99 & 0.98 \\
\hline Hedge long side $\sigma(\varepsilon)$ & & $8.3 \%$ & $5.6 \%$ & $5.5 \%$ & $7.2 \%$ & $5.4 \%$ & $5.5 \%$ \\
\hline Hedge short side $\alpha$ & & $8.5 \%$ & $6.8 \%$ & $6.8 \%$ & $8.0 \%$ & $6.5 \%$ & $6.9 \%$ \\
\hline Hedge short side $\beta$ & & -1.48 & -1.19 & -1.15 & -1.79 & -1.31 & -1.26 \\
\hline Hedge short side $\sigma(\mathrm{e})$ & & $20.8 \%$ & $10.1 \%$ & $9.7 \%$ & $28.4 \%$ & $11.4 \%$ & $13.2 \%$ \\
\hline \# monthly obs & & 408 & 408 & 408 & 408 & 408 & 408 \\
\hline
\end{tabular}

Notes:

1. Following BSCV, we define annualized returns as the sum of calendar monthly returns.

2. Betas $(\beta)$ are calculated against the VW market. 
Table 4: Brandt, Santa-Clara and Valkanov's (BSCV, 2009) linear parametric portfolio policy (PPP) applied to stock-price-based and accounting-based firm characteristics: With no-short-sales restriction imposed

This table reports the results of estimating the coefficients of the linear portfolio weight function specified in equation (3) with respect to three stock-price-based firm characteristics (PBCs: market capitalization, book-to-market, momentum) and three accounting-based firm characteristics (ABCs: accruals, unexpected earnings, asset growth). The optimization problem in equation (10) uses a power utility function with relative risk aversion of 5. Data restrictions and variable definitions are given in Table 1. Relative to Table 2, this table imposes the restriction that no short sales are allowed.

Panel A: Parameter estimates, average portfolio weights, and average firm characteristics in the optimal portfolios

\begin{tabular}{|c|c|c|c|c|c|c|c|}
\hline & & \multicolumn{3}{|c|}{$\begin{array}{c}\text { PPP in-sample } \\
\text { Estimation period is Jan. } 1975 \text { - Dec. } 2008\end{array}$} & \multicolumn{3}{|c|}{$\begin{array}{c}\text { PPP out-of-sample } \\
\text { Monthly over Jan. } 1975 \text { - Dec. } 2008\end{array}$} \\
\hline & VW market & PBCs & $\mathrm{ABCs}$ & $\mathrm{PBCs}+\mathrm{ABCs}$ & PBCs & $\mathrm{ABCs}$ & $\mathrm{PBCs}+\mathrm{ABCs}$ \\
\hline$\theta_{\mathrm{me}}$ & & -4.3 & & -4.2 & -3.1 & & -0.8 \\
\hline$\theta_{\mathrm{btm}}$ & & 19.5 & & 19.1 & 24.2 & & 30.6 \\
\hline$\theta_{\mathrm{mom}}$ & & 7.8 & & 4.6 & 12.1 & & 7.9 \\
\hline$\theta_{\mathrm{acc}}$ & & & 0.2 & -0.3 & & 0.8 & 0.4 \\
\hline$\theta_{\text {ue }}$ & & & 10.1 & 6.8 & & 1.7 & 15.4 \\
\hline$\theta_{\text {agr }}$ & & & -0.1 & 0.6 & & -0.4 & 0.3 \\
\hline Avg. $\left|w_{i}\right| \times 100$ & 0.03 & 0.03 & 0.03 & 0.03 & 0.03 & 0.03 & 0.03 \\
\hline Avg. $\max w_{i} \times 100$ & 3.2 & 1.0 & 1.6 & 1.0 & 0.8 & 2.8 & 0.7 \\
\hline Avg. $\min w_{i} \times 100$ & 0.0 & 0.0 & 0.0 & 0.0 & 0.0 & 0.0 & 0.0 \\
\hline Avg. $\Sigma w_{i} I\left(w_{i}<0\right)$ & 0.0 & 0.0 & 0.0 & 0.0 & 0.0 & 0.0 & 0.0 \\
\hline Avg. $\sum I\left(w_{i} \leq 0\right) / N_{t}$ & 0.0 & 0.45 & 0.43 & 0.45 & 0.45 & 0.31 & 0.45 \\
\hline Avg. weighted MVE & 0.41 & -0.05 & & -0.05 & -0.05 & & -0.04 \\
\hline Avg. weighted BTM & -0.12 & 0.26 & & 0.25 & 0.26 & & 0.25 \\
\hline Avg. weighted MOM & 0.04 & 0.06 & & 0.06 & 0.09 & & 0.07 \\
\hline Avg. weighted ACC & & & 0.01 & 0.00 & & 0.00 & 0.01 \\
\hline Avg. weighted UE & & & 0.24 & 0.05 & & 0.09 & 0.09 \\
\hline Avg. weighted AGR & & & 0.06 & -0.06 & & 0.02 & -0.05 \\
\hline
\end{tabular}

Panel B: Descriptive statistics on the annualized returns generated by the optimal portfolios

\begin{tabular}{|l|c|ccc|ccc|}
\hline Certainty equivalent $r$ & $6.2 \%$ & $24.8 \%$ & $7.9 \%$ & $24.9 \%$ & $23.6 \%$ & $5.6 \%$ & $23.8 \%$ \\
Mean $r$ & $12.7 \%$ & $18.6 \%$ & $14.4 \%$ & $18.7 \%$ & $18.5 \%$ & $13.4 \%$ & $18.6 \%$ \\
$\sigma(r)$ & $15.4 \%$ & $17.1 \%$ & $18.3 \%$ & $17.2 \%$ & $17.0 \%$ & $16.2 \%$ & $17.2 \%$ \\
Sharpe ratio & 0.45 & 0.76 & 0.47 & 0.76 & 0.76 & 0.48 & 0.75 \\
$\alpha$ & & $6.4 \%$ & $0.1 \%$ & $6.5 \%$ & $6.4 \%$ & $0.3 \%$ & $6.3 \%$ \\
$\beta$ & & 0.96 & 1.12 & 0.96 & 0.96 & 1.03 & 0.97 \\
$\sigma(\varepsilon)$ & & $8.6 \%$ & $5.9 \%$ & $8.6 \%$ & $8.4 \%$ & $2.5 \%$ & $8.5 \%$ \\
Information ratio & & 0.75 & 0.02 & 0.76 & 0.76 & 0.12 & 0.74 \\
\hline Optimized mean $r=\mathrm{A}$ & $12.7 \%$ & $18.6 \%$ & $14.4 \%$ & $18.7 \%$ & $18.5 \%$ & $13.4 \%$ & $18.6 \%$ \\
Mkt $r=\mathrm{B}$ & $12.7 \%$ & $12.7 \%$ & $12.7 \%$ & $12.7 \%$ & $12.7 \%$ & $12.7 \%$ & $12.7 \%$ \\
Managed rlev = A - B & $0.0 \%$ & $5.9 \%$ & $1.7 \%$ & $6.0 \%$ & $5.8 \%$ & $0.7 \%$ \\
\hline
\end{tabular}

Notes:

1. Following Brandt, Santa-Clara and Valkanov (2009), we define annualized returns as the sum of calendar monthly returns.

2. Betas $(\beta)$ are calculated against the VW market.

3. Standard errors for estimated parameters are not reported. We are still evaluating alternative approaches to calculating them. 
Table 5: Linear parametric portfolio policy (PPP) applied to stock-price-based and accounting-based firm characteristics: After taking alternative proxies for transactions costs into account

This table reports the results of estimating the coefficients of the linear portfolio weight function specified in equation (3) with respect to three stock-price-based firm characteristics (PBCs: market capitalization, book-to-market, momentum) and three accounting-based firm characteristics (ABCs: accruals, unexpected earnings, asset growth). The optimization problem in equation (10) uses a power utility function with relative risk aversion of 5. Data restrictions and variable definitions are given in Table 1. Relative to Tables 2-4, this table incorporates either constant one-way trading costs of $0.5 \%$, or size-based and timevarying one-way trading costs as given in equation (12) of the text.

Panel A: Selected Table 2 results after taking into account estimated transactions costs on portfolio turnover

\begin{tabular}{|c|c|c|c|c|c|c|}
\hline \multirow{2}{*}{$\begin{array}{l}\text { All observations, no } \\
\text { short-sale constraints }\end{array}$} & \multicolumn{3}{|c|}{ Constant one-way trading costs of $0.5 \%$} & \multicolumn{3}{|c|}{ Size-based and time-varying one-way trading costs } \\
\hline & PBCs & $\mathrm{ABCs}$ & $\mathrm{PBCs}+\mathrm{ABCs}$ & PBCs & $\mathrm{ABCs}$ & $\mathrm{PBCs}+\mathrm{ABCs}$ \\
\hline Avg. monthly turnover & 1.06 & 2.16 & 2.46 & 1.06 & 2.16 & 2.46 \\
\hline Mean $r$ & $35.7 \%$ & $45.1 \%$ & $60.7 \%$ & $27.1 \%$ & $29.5 \%$ & $42.5 \%$ \\
\hline$\sigma(r)$ & $26.7 \%$ & $30.7 \%$ & $36.7 \%$ & $26.6 \%$ & $32.2 \%$ & $37.7 \%$ \\
\hline Sharpe ratio & 1.13 & 1.28 & 1.50 & 0.80 & 0.74 & 0.98 \\
\hline$\alpha$ & $34.2 \%$ & $37.5 \%$ & $59.7 \%$ & $25.8 \%$ & $22.4 \%$ & $42.0 \%$ \\
\hline Information ratio & 1.29 & 1.28 & 1.63 & 0.97 & 0.72 & 1.12 \\
\hline
\end{tabular}

Panel B: Selected Table 3 results after taking into account estimated transactions costs on portfolio turnover

\begin{tabular}{|l|ccc|ccc|}
\hline \multirow{2}{*}{$\begin{array}{l}\text { Largest 500 firms, no } \\
\text { short-sale constraints }\end{array}$} & \multicolumn{2}{|c|}{ Constant one-way trading costs of 0.5\% } & \multicolumn{3}{c|}{ Size-based and time-varying one-way trading costs } \\
\cline { 2 - 7 } Avg. monthly turnover & PBCs & ABCs & PBCs + ABCs & PBCs & ABCs & PBCs + ABCs \\
Mean $r$ & 0.24 & 0.75 & 0.95 & 0.24 & 0.75 & 0.95 \\
$\sigma(r)$ & $13.0 \%$ & $22.5 \%$ & $26.7 \%$ & $10.3 \%$ & $15.3 \%$ & $17.5 \%$ \\
Sharpe ratio & $20.3 \%$ & $22.6 \%$ & $30.7 \%$ & $20.5 \%$ & $23.1 \%$ & $31.4 \%$ \\
$\alpha$ & 0.36 & 0.75 & 0.69 & 0.22 & 0.42 & 0.38 \\
Information ratio & $2.9 \%$ & $16.3 \%$ & $18.5 \%$ & $0.2 \%$ & $9.2 \%$ & $9.3 \%$ \\
\hline
\end{tabular}

Panel C: Selected Table 4 results after taking into account estimated transactions costs on portfolio turnover

\begin{tabular}{|l|ccc|ccc|}
\hline \multirow{2}{*}{$\begin{array}{l}\text { All observations, with } \\
\text { short-sales disallowed }\end{array}$} & \multicolumn{2}{|c|}{ Constant one-way trading costs of 0.5\% } & \multicolumn{3}{c|}{ Size-based and time-varying one-way trading costs } \\
\cline { 2 - 7 } & PBCs & ABCs & PBCs + ABCs & PBCs & ABCs & PBCs + ABCs \\
\hline Avg. monthly turnover & 0.13 & 0.07 & 0.14 & 0.13 & 0.07 & 0.14 \\
Mean $r$ & $17.8 \%$ & $13.0 \%$ & $17.8 \%$ & $16.7 \%$ & $12.4 \%$ & $16.6 \%$ \\
$\sigma(r)$ & $17.0 \%$ & $16.2 \%$ & $17.2 \%$ & $16.9 \%$ & $16.1 \%$ & $17.1 \%$ \\
Sharpe ratio & 0.71 & 0.45 & 0.70 & 0.65 & 0.42 & 0.64 \\
$\alpha$ & $5.6 \%$ & $-0.1 \%$ & $5.5 \%$ & $4.6 \%$ & $-0.6 \%$ & $4.4 \%$ \\
Information ratio & 0.67 & -0.06 & 0.65 & 0.55 & -0.26 & 0.52 \\
\hline
\end{tabular}

Notes:

1. Following Brandt, Santa-Clara and Valkanov (2009), we define annualized returns as the sum of calendar monthly returns.

2. Alphas $(\alpha)$ are calculated after adjusting for $\beta$ risk against the VW market. 


\section{References}

Agarwal, V., and N.Y. Naik, 2004. Risks and portfolio decisions involving hedge funds", Review of Financial Studies 17, 1, 63-98.

Ait-Sahalia, Y., and M.W. Brandt, 2001. Variable selection for portfolio choice. Journal of Finance 56, 1297-1351.

Alexander, G.J., 1993. Short selling and efficient sets. Journal of Finance 48, 1497-1506.

Asness, C., Krail, R., and J. Liew, 2001. Do hedge funds hedge? Journal of Portfolio Management Fall, 6-19.

Ball, R.J., and P. Brown, 1968. An empirical evaluation of accounting income numbers. Journal of Accounting Research 6, 159-178.

Banz, R., 1981. The relationship between return and market value of common stocks. Journal of Financial Economics 9, 3-18.

Bernard, V.L., and J.K. Thomas, 1989. Post-earnings-announcement drift: Delayed price response or risk premium? Journal of Accounting Research 27, 1-36.

Bernard, V.L., and J.K. Thomas, 1990. Evidence that stock prices do not fully reflect the implications of current earnings for future earnings. Journal of Economics \& Accounting 13, 305-340.

Brandt, M.W., Santa-Clara, P., and R. Valkanov, 2009. Parametric portfolio policies: Exploiting characteristics in the cross section of equity returns. Review of Financial Studies 22: 34113447.

Brown, G.W., Green, J., and J.R.M. Hand, 2009. Hedge funds and the crisis: Scapegoats or culprits? Working paper, UNC Chapel Hill.

Cooper, M.J., Gulen, H., and M.J. Schill, 2008. Asset growth and the cross-section of stock returns. Journal of Finance 63, 1609-1651.

Cooper, M.J., Gulen, H., and M.J. Schill, 2009. The asset growth effect in stock returns. Working paper, University of Utah.

Foster, G., Olsen, C., and T. Shevlin, 1984. Earnings releases, anomalies, and the behavior of security prices. The Accounting Review, 4, 574-603

Green, J., Hand, J.R.M., and M. Soliman, 2009. Going, going, gone? The demise of the accruals anomaly. Working paper, UNC Chapel Hill.

Green, R.C., and B. Hollifield, 1992. When will mean-variance efficient portfolios be well diversified? Journal of Finance 47, 1785-1809.

Grinold, R.C., 1992. Are benchmark portfolios efficient? The Journal of Portfolio Management 19, 1, 34-40.

Grinold, R.C., and R.N. Kahn, 2000. Active portfolio management: A quantitative approach for producing superior returns and controlling risk. $2^{\text {nd }}$ Edition, McGraw-Hill.

Haugen, R.A., and N.L. Baker, 1996. Commonality in the determinants of expected stock 
returns. Journal of Financial Economics 41, 401-439.

Hirschleifer, D., Hou, K., and W.H. Teoh, 2006. The accrual anomaly: Risk or mispricing? Working paper, Ohio State University.

Jacobs, B.R., and K.N. Levy, 1993. Long/short equity investing: Profit from both winners and losers. Journal of Portfolio Management 20 (1), 52-63.

Jacobs, B.R., and K.N. Levy, 1997. The long and short on long-short. The Journal of Investing (Spring) 2-15.

Jegadeesh, N., 1990. Evidence of predictable behavior of security returns. Journal of Finance $45,881-898$.

Jegadeesh, N., and S. Titman, 1993. Returns to buying winners and selling losers: Implications for stock market efficiency. Journal of Finance 48, 65-91.

Jones, S.L, and G. Larsen, 2004. How short selling expands the investment opportunity set and improves upon potential portfolio efficiency. In Short selling: Strategies, risks, and rewards. Ed. F. Fabozzi, Wiley Finance.

Khandani, A.E., and A. Lo, 2007. What happened to the quants in August 2007? Working paper, MIT.

Khandani, A.E., and A. Lo, 2008. What happened to the quants in August 2007? Evidence from factors and transactions data. Working paper, MIT.

Korkie, B., and H.J. Turtle, 2002. A mean-variance analysis of self-financing portfolios. Management Science 48 (3), 427-443.

Kothari, S.P., 2001. Capital markets research in accounting. Journal of Economics \& Accounting 31, 105-231.

Kothari, S.P., and J. Shanken, 2002. Anomalies and efficient portfolio formation. Research monograph, The Research Foundation of AIMR ${ }^{T M}$.

Lee, M.C., 2001. Market efficiency and accounting research: a discussion of 'capital market research in accounting' by S.P. Kothari. Journal of Economics \& Accounting 31, 233-253.

Levy, H., 1983. The capital asset pricing model: Theory and evidence. Economic Journal 93, $145-165$.

Levy, M., and Y. Ritov, 2001. Portfolio optimization with many assets: The importance of short-selling. Working paper, Hebrew University of Jerusalem.

Lo, A.W., 2002. The statistics of Sharpe ratios. Financial Analysts Journal, July/August 36-51.

Lo, A.W., 2008. Hedge funds: An analytic perspective. Princeton University Press, Princeton NJ.

Magill, M.M., and G.M. Constantinides, 1976. Portfolio selection with transaction costs. Journal of Economic Theory 13, 245-263.

Markowitz, H.M., 1952. Portfolio selection. Journal of Finance 7, 77-91.

Mashruwala, C., Rajgopal, S., and T. Shevlin, 2006. Why is the accruals anomaly not arbitraged 
away? The role of idiosyncratic risk and transactions costs. Journal of Accounting \& Economics 42, 3-33.

Michaud, R.O., 1989. The Markowitz optimization enigma: Is 'optimized' optimal? Financial Analysts Journal (January-February): 31-42.

Penman, S.H., 2009. Financial statement analysis and security valuation. McGraw-Hill/Irwin.

Reinganum, M.R., 1981. Misspecification of capital asset pricing: Empirical anomalies based on earnings' yields and market values. Journal of Financial Economics 9, 19-46.

Rosenberg, B., Reid, K., and R. Lanstein, 1985. Persuasive evidence of market inefficiency. Journal of Portfolio Management 11, 9-17.

Shumway, T., and V. Warther, 1999. The delisting bias in CRSP's Nasdaq data and its implications for the size effect. Journal of Finance, 2361-2379.

Sharpe, W.F., 1994. The Sharpe ratio. Journal of Portfolio Management 21 (1), 49-58.

Sloan, R.G., 1996. Do stock prices fully reflect information in accruals and cash flows about future earnings? The Accounting Review 71, 3, 289-315. 